Elizabete Wenzel de Menezes

\title{
BASES CIENTÍFICAS E PRÁTICAS PARA DISSEMINAR A UTILIZAÇÃO DE CARBOIDRATOS NÃO-DISPONÍVEIS NA ALIMENTAÇÃO
}

Texto crítico sistematizado apresentado para - Concurso de Livre-Docência junto ao Departamento de Alimentos e Nutrição Experimental da Faculdade de Ciências Farmacêuticas da Universidade de São Paulo

São Paulo 2008 


\section{SUMÁRIO}

Pág.

Lista de abreviaturas .................................................................................................

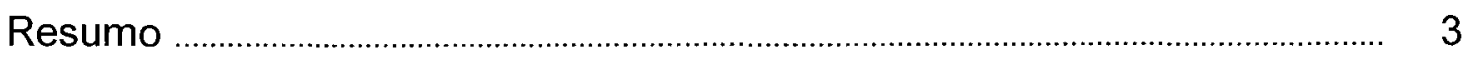

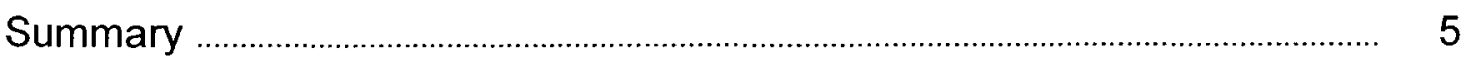

1. Introdução .................................................................................................. 7

1.1 Carboidratos e fibra alimentar ........................................................................... 7

1.2 Aproveitamento de carboidratos de alimentos: estudos in vitro e in vivo

1.3 Banco de dados e tabelas de composição de alimentos ......................... 33

2. Comentários finais e perspectivas futuras ...................................................... 39

3. Referências bibliográficas ..................................................................................... 41

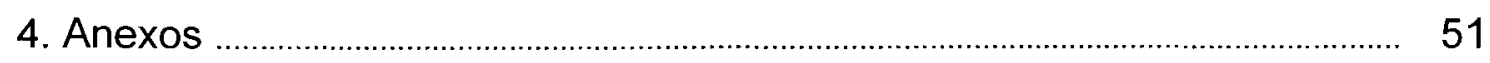

Anexo 1 - Trabalho apresentado: LAJOLO, FM; MENEZES, EW; FILISETTI-COZZI, TMCC. Considerações sobre carboidratos e fibra. Arch. Latinoamer. Nutr., v.38 (3), p.519-542, 1988 ....................

Anexo 2 - Trabalho apresentado: VANNUCCHI, H; MENEZES, EW; CAMIPANA, AO; LAJOLO, FM, eds. Aplicação das recomendações nutricionais adaptadas à população brasileira. Cadernos de Nutrição, SBAN, Ribeirão Preto, v.2, 1990. 155

Anexo 3 - Trabalho apresentado: UNIVERSIDADE DE SÃO PAULO (USP). Tabela Brasileira de Composição de Alimentos-USP, BRASILFOODS, Faculdade de Ciências Farmacêuticas, Departamento de Alimentos e Nutrição Experimental, São Paulo, 1998. Coordenação: MENEZES, EW; LAJOLO, FM. Disponível em: http://www.fcf.usp.br/tabela

Anexo 4 - Trabalho apresentado: CARUSO, L; LAJOLO, FM; MENEZES, EW. Modelos esquemáticos para avaliação da qualidade analítica dos dados nacionais de fibra alimentar. Ci. Tecnol. Aliment., v.19 (3), p.406-412, 1999

Anexo 5 - Trabalho apresentado: MENEZES, EW; CARUSO, L; LAJOLO, FM. An application of criteria to evaluate quality of dietary fibre data in Brazilian foods. J. Food Compos. Anal., v.13 (4), p.455-473, 2000

Anexo 6 - Trabalho apresentado: LAJOLO, FM; MENEZES, EW. Dietary fiber and resistant starch intake in Brazil: Recommendations and actual consumption patterns. In: CHO, SS; DREHER, ML, eds. Handbook of dietary fiber. Marcel Dekker NY, NY, 2001. p.845858 
Anexo 7 - Trabalho apresentado: MENEZES, EW; GIUNTINI, EB; LAJOLO, FM. Perfil da ingestão de fibra alimentar e amido resistente pela população brasileira nas últimas três décadas. In: LAJOLO, FM; SAURA-CALIXTO, F; WITTIG DE PENNA, E; MENEZES, EW, eds. Fibra dietética en lberoamérica: Tecnología y salud. Obtención, caracterización, efecto fisiológico y aplicación en alimentos. CYTED, CNPq, Varela, São Paulo, 2001. p.433-444

Anexo 8 - Trabalho apresentado: MENEZES, EW; LAJOLO, FM, eds. Contenido en fibra dietética y almidón resistente en alimentos y productos iberoamericanos. Proyecto CYTED XI.6 "Obtención y caracterización de fibra dietética para su aplicación en regímenes especiales", CNPq, Docuprint, São Paulo, 2000. 121p. (ISBN- 85901225-1-4)

Anexo 9 - Trabalho apresentado: GIUNTINI, EB; MENEZES, EW; LAJOLO, FM. Potencial de fibra alimentar em países iberoamericanos: Alimentos, produtos e resíduos. Arch. Latinoam. Nutr., v.53 (1), p.14-20, 2003

Anexo 10 - Trabalho apresentado: LAJOLO, FM; SAURA-CALIXTO, F; WITTIG DE PENNA, E, MENEZES, EW, eds. Fibra dietética en Iberoamérica: Tecnología y salud. Obtención, caracterización, efecto fisiológico y aplicación en alimentos. Proyecto CYTED XI.6 "Obtención y caracterización de fibra dietética para su aplicación en regímenes especiales", CNPq. Varela, São Paulo, 2001. 469p. (ISBN - 85-85519-59-2)

Anexo 11 - Trabalho apresentado: LAJOLO, FM; MENEZES, EW, eds. Carbohidratos en alimentos regionales iberoamericanos. Proyecto CYTED XI.18 "Composición, estructura, propiedades biológicas de carbohidratos y su utilización en alimentos", CNPq, EDUSP, São Paulo, 2006. 648 p. (ISBN 85-314-0935-7)

Anexo 12 - Trabalho apresentado: ROSIN, PM; LAJOLO, FM; MENEZES, EW. Measurement and characterization of dietary starches. J. Food Compos. Anal., v. 15 (4), p.367-377, 2002

Anexo 13 - Trabalho apresentado: MENEZES, EW; MELO, AT; LIMA, G; LAJOLO, FM. Measurement of carbohydrate components and their impact on energy value of foods. J. Food Compos. Anal., v.17 (34), p.331-338, 2004

Anexo 14 - Trabalho apresentado: MENEZES, EW; GIUNTINI, EB. Fibra alimentar. In: PHILIPPI, ST, ed. Pirâmide dos alimentos: Fundamentos básicos da nutrição. Manole, São Paulo, 2008. p.341-362

Anexo 15 - Trabalho apresentado: MENEZES, EW; LAJOLO, FM Utilização do amido de leguminosas. Arch. Latinoam. Nutr., v.45 (1), p.S270-S272, 1995 
Anexo 16 - Trabalho apresentado: MENEZES, EW; LAJOLO, FM; SERAVALLI, EAG; VANNUCCHI, H; MOREIRA, EA. Starch availability in Brazilian foods: "in vivo" and "in vitro" assays. Nutr. Res., v.16 (8), p.1425-1436, 1996

Anexo 17 - Trabalho apresentado: MENEZES, EW; LAJOLO, FM. Aproveitamento do amido do feijão em ensaios de média duração com animais. Ci. Tecnol. Aliment., v.17 (1), p.2-6, 1997

Anexo 18 - Trabalho apresentado: MENEZES, EW; LAJOLO, FM. Índice glicêmico de alimentos. In: MENEZES, EW; LAJOLO, FM, eds. Avances sobre el uso y las propiedades de los carbohidratos de los alimentos regionales. J K Color Gráfica e Editora Ltda., São Paulo, 2003. p.53-60

Anexo 19 - Trabalho apresentado: CARREIRA, MC; LAJOLO, FM; MENEZES, EW. Glycemic index: Effect of food storage under low temperature. Braz. Arch. Biol. Technol., v.47 (4), p.569-574, 2004

Anexo 20 - Trabalho apresentado: MENEZES, EW; LAJOLO, FM. Marcadores in vivo e in vitro de carboidratos In: LAJOLO, FM; MENEZES, EW, eds. Carbohidratos en alimentos regionales iberoamericanos. Proyecto CYTED XI.18 "Composición, estructura, propiedades biológicas de carbohidratos y su utilización en alimentos", CNPq, EDUSP, São Paulo, 2006. p.309-334

Anexo 21 - Trabalho apresentado: CORDENUNSI, BR; MIENEZES, EW; GENOVESE, MI; COLLI, C; SOUZA, AG; LAJOLO, FM. Chemical composition and glycemic index of Brazilian pine (Araucaria angustifolia) seeds. J. Agr. Food Chem., v.52 (11), p.3412-3416, 2004

Anexo 22 - Trabalho apresentado: MENEZES, EW; GIUNTINI, EB; DAN, M; LAJOLO, FM. TBCA-USP/ BRASILFOODS: Carbohydrate database. Anais da $7^{\text {th }}$ International Food Data Conference. São Paulo, 2007. p.44. [Conferência realizada em São Paulo, SP, Brasil, de 21 a 24 de outubro de 2007]

Anexo 23 - Trabalho apresentado: PASCOAL, GB; LAJOLO, FM; MENEZES, EW. Effects of fructans, deriving from onion (Allium cepa L), on indigestible carbohydrates fermentation: in vivo study. Anais do $18^{\text {th }}$ International Congress of Nutrition. Durban, 2005. [Congresso realizado em Durban, África do Sul, de 19 a 23 de setembro de 2005]

Anexo 24 - Trabalho apresentado: SOUZA, MCC; LAJOLO, FM; MARTINI, LA; CORREA, NAB; DAN, MCT; MENEZES, EW. Effect of oligofructose-enriched inulin on bone metabolism of girls with low calcium intakes. Braz. Arch. Biol. Technol. (enviado para publicação em dezembro de 2007) 
Anexo 25 - Trabalho apresentado: TRIBESS, TB; TADINI, CC; MENEZES, EW; LAJOLO, FM. Estudo do efeito do pré-tratamento químico na coloração da farinha de banana verde. Anais do Simpósio Brasileiro sobre o desenvolvimento de novos produtos alimentícios. ITAL, Campinas. 2006. [Simpósio realizado em Campinas, de 08 a 09 de maio de 2006]

Anexo 26 - Depósito de pedido de patente de invenção: MENEZES, EW; LAJOLO, FM; TADINI, C; TRIBES, T. Processo de produção de farinha proveniente da banana verde. Instituto Nacional de Propriedade Industrial - I.N.P.I./SP, em 12 de julho de 2007, protocolo $\mathrm{n}^{\circ} 018070044163$

Anexo 27 - Trabalho apresentado: VIDAL, T; TRIBESS, TB; MENEZES, EW; TADINI, CC. Produção de barra de cereais diet sabor banana com adição de farinha de banana verde (Musa Cavendishii, Var. Nanicão). Anais do Simpósio Latino Americano de Ciência dos Alimentos (SLACA), Campinas, São Paulo, 2007. [Simpósio realizado em Campinas, São Paulo, de 4 a 7 de novembro de 2007]

Anexo 28 - Trabalho apresentado: MENEZES, EW; GONÇALVES, FAR; GIUNTINI, EB; LAJOLO, FM. Brazilian food composition database: Internet dissemination and other recent developments. J. Food Compos. Anal., v. 15 (4), p.453-462, 2002

Anexo 29 - Trabalho apresentado: MENEZES, EW; GIUNTINI, EB; LAJOLO, FM. A questão da variabilidade e qualidade de dados de composição de alimentos. Nutrire, v.26, p.63-76, 2003

Anexo 30 - Trabalho apresentado: MENEZES, EW; RATTO, AT; GIUNTINI, EB; LAJOLO, FM. Composição de alimentos: compilação e uniformização de estruturas para intercâmbio de dados. Braz. J. Food Technol., v.8 (1), p.25-33, 2005

Anexo 31 - Trabalho apresentado: GIUNTINI, EB; LAJOLO, FM; MENEZES, EW. Tabela Brasileira de Composição de Alimentos TBCA-USP (Versões 3 e 4) no contexto internacional. Arch. Latinoam. Nutr., v.56 (4), p.366-374, 2006

Anexo 32 - Trabalho apresentado: MENEZES, E W; GIUNTINI, EB. Tabelas e bancos de dados de composição de alimentos. In: DUTRA-de-OLIVEIRA, JE; MARCHINI, JS, eds. Ciências nutricionais. $2^{a}$ ed. Sarvier, São Paulo, 2008, (no prelo)

Este trabalho sistematiza criticamente parte da obra do autor 


\section{LISTA DE ABREVIATURAS}

ABV

AGCC

ANVISA

AR

ARD

BRASILFOODS

CG

$\mathrm{CNPq}$

CYTED

DCNT

EUROFIR

FA

FAO

FAO

FBV

FCF

IG

INFOODS

INTA

LATINFOODS

MBV

$\mathrm{OC}$

POF

PTHi

TBCA-USP

UNU

USDA

USP

WHO
Amido isolado de banana verde

Ácidos graxos de cadeia curta

Agência Nacional de Vigilância Sanitária do Ministério da

Saúde

Amido resistente

Amido de rápida digestão

Rede Brasileira de Dados de Composição de Alimentos

Carga glicêmica

Conselho Nacional de Desenvolvimentos Cieritífico e

Tecnológico

Ciencia y Tecnología para el Desarrollo

Doenças crônicas não-transmissíveis

European Food Information Resource Network

Fibra alimentar

Food and Agriculture Organization of the United Nations

Fosfatase alcalina fração específica óssea

Farinha de banana verde

Faculdade de Ciências Farmacêuticas

Índice glicêmico

International Network of Food Data Systems

Instituto de Nutrición y Tecnología de los Alimentos

Red Latinoamericana de Datos de Composición de

Alimentos

Farinha de banana verde cozida com casca

Osteocalcina

Pesquisa de orçamento familiar

Paratormônio intacto

Tabela Brasileira de Composição de Alimentos - USP

United Nations University

U.S. Department of Agriculture

Universidade de São Paulo

World Health Organizations 


\section{RESUMO}

Sabe-se hoje que os carboidratos não-disponiveis, entre os quais a fibra alimentar está inclusa, participam na prevenção e no tratamento das doenças crônicas não-transmíssiveis. Entretanto, durante os últimos 20 anos, uma série de discussões surgiram sobre estes compostos, sem que existissem respostas pertinentes para algumas delas. Entre os questionamentos nacionais estão: Qual a ingestão de fibra alimentar pela população brasileira? Qual o real conteúdo de fibra alimentar presente nos alimentos brasileiros? Qual o perfil de digestão e absorção dos carboidratos no intestino delgado? Qual o perfil de utilização dos carboidratos não-disponíveis no intestino grosso? Qual o conteúdo dos outros nutrientes presentes nos alimentos brasileiros? Existem alternativas alimentares para facilitar a ingestão de carboidratos nãodisponiveis?

Este trabalho descreve e discute aspectos científicos e práticos, desenvolvidos pelo grupo, necessários para responder parte dos questionamentos mencionados e viabilizar a utilização de carboidratos nãodisponíveis na alimentação. O trabalho está dividido em três tópicos: 1) Carboidratos e fibra alimentar; 2) Aproveitamento de carboidratos de alimentos: estudos in vitro e in vivo; 3) Banco de dados e tabelas de composição de alimentos. Em cada tópico, estão apresentadas parte das investigações realizadas pelo grupo e as nossas contribuições sobre o assunto. 


\section{SUMMARY}

It is well known, nowadays, that unavailable carbohydrates, including dietary fiber, are involved in the prevention and treatment of non-transmissible chronic diseases. Nevertheless, for the last 20 years, several discussions about these compounds have been brought up, but some of them have not been answered. Among the national questions, there are: what is the ingestion of dietary fiber by the Brazilian population? What is the real content of dietary fiber in the Brazilian foods? What is the profile of digestion and absorption of carbohydrates in the small intestine? What is the profile of unavailable carbohydrate utilization in the large intestine? What is the content of other nutrients in the Brazilian foods? Are there any diet alternatives to facilitate the ingestion of unavailable carbohydrates?

This work describes and discusses scientific and practical aspects, which have been developed by the group, necessary to answer part of the questions mentioned above and to facilitate the utilization of unavailable carbohydrates in the diet. The present work is divided in three topics: 1) Carbohydrates and dietary fiber; 2) Bioavailability of food carbohydrates: in vitro and in vivo studies; 3) Food composition tables and databases. In each topic, part of the researches done by the group is shown, as well as our contributions on the subject. 


\section{INTRODUÇÃO}

\subsection{Carboidratos e fibra alimentar}

Os guias de alimentação orientam que os carboidratos devam responder por mais de $50 \%$ da energia total da dieta, a qual deve ser proveniente de variadas fontes, e enfatizam o consumo de cereais, raízes, leguminosas, legumes, verduras e frutas. Ressaltam, também, que os alimentos devam ser consurnidos, preferencialmente, na forma integral, pois contêm outros nutrientes além dos carboidratos (BENGOA et al., 1988; NATIONAL RESEARCH COUNCIL, 1989; VANNUCCHI, et al., 1990, Anexo 2; FAO; WHO, 1998; LAJOLO et al., 2001, Anexo 10; WHO; FAO, 2003; GRAY, 2006; MANN et al., 2007).

A fibra alimentar (FA) produz inúmeros efeitos fisiológicos, podendo ser classificada como prebiótico ou não, e pode contribuir de forma significativa para a prevenção e tratamento das doenças crônicas não-transmissíveis (DCNT). A FA está relacionada à prevenção de diabetes, doenças cardiovasculares, síndrome do cólon irritável, obesidade, diverticulose e câncer cólo-retal, uma vez que tem propriedades para atuar na retenção de água no cólon distal e de adsorver compostos carcinogênicos e ácidos biliares, reduzir o $\mathrm{pH}$ do ceco, auxiliar na perda de peso, proporcionar saciedade, promover redução de colesterol e triacilglicerol plasmáticos, prevenir constipação intestinal, diminuir a glicemia pós-prandial, entre outras (LAJOLO et al., 2001, Anexo 10; LAJOLO; MIENEZES, 2006, Anexo 11; GRAY, 2006; MANN, 2007; VENN; GREEN, 2007; van DAM; SEIDELL, 2007; KEY; SPENCER, 2007).

Segundo a WHO; FAO (2003), as metas de ingestão alimentar propostas para a prevenção de DCNT enfatizam a ingestão adequada de fibra alimentar. Com relação à ingestão diária de carboidratos e FA, os carboidratos totais devem corresponder a $55-75 \%$ da energia total e a ingestão de fibra alimentar total deve ser maior que $25 \mathrm{~g} /$ dia ou mais de $20 \mathrm{~g}$ no caso de polissacarídeos não-amido, sendo que o consumo de frutas e vegetais deve ser maior de $400 \mathrm{~g} / \mathrm{dia}$. Estas diretrizes estão baseadas em evidências (comprovadas, prováveis e possiveis) sobre a prevenção de DCNT.

Em 1988 foi realizado em Caracas, Venezuela, de 22 a 28 de novembro de 1987, o Taller "Guias de Alimentación - bases para su desarrollo en America 
Latina", organizado pela Fundación Cavendes e United Nations University (UNU). Esse evento contou com a participação de um grupo de especialistas na área de nutrição, e teve como objetivo estabelecer os princípios para elaboração de guias de alimentação de acordo com as características ecológicas, sócio-econômicas e culturais da região, considerando, também, as doenças nutricionais, os hábitos alimentares e os alimentos disponiveis. Baseados nos conhecimentos disponiveis na época, as recomendações nutricionais internacionais para energia e nutrientes foram adaptadas para a América Latina e foram estabelecidos critérios a serem considerados, por cada país, quando da elaboração de seus guias de alimentação (BENGOA et al., 1988).

Nosso grupo de pesquisa, coordenado pelo Prof. Franco M. Lajolo, foi convidado para participar desse evento. Em função da experiência do grupo, o tema "Carboidratos e fibra" ficou sob nossa responsabilidade. Elaboramos uma detalhada revisão sobre o assunto, a qual foi publicada como capitulo de um informe completo do evento (LAJOLO; MENEZES; FILISETTI-COZZI, 1988b) e nos Archivos Latinoamericanos de Nutrición, em 1988 (LAJOLO; MENEZES; FILISETTI-COZZI, 1988a, Anexo 1).

O artigo do anexo 1 (LAJOLO; MENEZES; FILISETTI-COZZI, 1988a, Anexo 1) incluiu detalhada revisão sobre carboidratos e fibra alimentar (FA) e serviu de base para a discussão e definição de metas nutricionais e guias alimentares para a América Latina. Nesse artigo foram discutidos: problemas de ingestão excessiva e deficiente de alimentos fonte de energia na América Latina; carboidratos simples e polissacarídeos ("complexos"); natureza da fibra alimentar (FA); definição de carboidratos e FA; efeitos fisiológicos e adversos da FA; problemas analíticos da FA; problemática relativa aos dados do conteúdo de FA dos alimentos da América Latina; dificuldades para a avaliação da ingestão de $F A$ e fontes de $F A$.

A partir desse documento e de minha exposição feita durante o evento, aspectos importantes relacionados à fibra alimentar foram amplamente discutidos, e determinadas decisões foram acatadas pelos representantes da comunidade ciertífica da região.

O primeiro aspecto de relevância refere-se ao conteúdo de fibra das tabelas de composição de alimentos da América Latina. Como as análises 
deste componente eram realizadas pelo método de "fibra bruta", e esta metodologia não era mais aceita mundialmente, os dados estavam totalmente errados. Este erro na determinação do conteúdo de fibra alimentar implica, conseqüentemente, em superestimação do conteúdo de carboidratos (calculados por diferença) e do aporte energético dos alimentos, especialmente em alimentos fontes de FA. Em resumo, um novo conceito sobre fibra alimentar ou fibra da dieta passou a ser adotado na América Latina, e no informe final da reunião (BENGOA et al., 1988), na página 14, foi incluída a seguinte frase, aqui retratada, na íntegra, do documento original: "Tablas de composición de Alimentos - Para una interpretación correcta de las Metas y la puesta en práctica de las Guías, es necesario contar con Tablas de Composición de Alimentos que sean completas y confiables. Las tablas disponibles en la actualidad para países de América Latina, deberán ser revisadas y actualizadas, particularmente en lo referente a fibra alimentaria y a diversos micronutrientes".

O segundo aspecto de relevância está relacionado à falta de informação sobre a ingestão de fibra alimentar e de carboidratos, bem como a precisa avaliação do aporte energético das dietas consumidas pela população da América Latina. Assim, foi recomendado que, após a geração e/ou compilação de dados de fibra alimentar, deveria ser avaliada a real ingestão deste componente e de carboidratos nos diferentes países.

Nosso grupo, entendendo que a adaptação desse informe para a população brasileira seria uma forma de facilitar a elaboração de guias alimentares, convidou pesquisadores da Faculdade de Medicina de Ribeirão Preto e de Botucatu para participarem da elaboração de publicação conjunta. Assim, adaptamos as informações do informe da América Latina (BENGOA et al., 1988) à realidade brasileira, e de acordo com as recomendações nutricionais do Recommended Dietary Allowances (NATIONAL RESEARCH COUNCIL, 1989), que tinham sido publicadas em 1989, resultando na publicação do livro "Aplicação das recomendações nutricionais adaptadas à população brasileira" (VANNUCCHI, et al., 1990, Anexo 2). O livro foi lançado durante o II Congresso Nacional da Sociedade Brasileira de Alimentação e Nutrição - SBAN "Guias Brasileiros de Alimentação", em São Paulo, de 28 a 31 de outubro de 1990. Cabe ressaltar que os 1000 exemplares impressos foram 
totalmente vendidos durante o evento, pois se tratava de um livro com informações básicas para prática de uma alimentação equilibrada.

$\mathrm{Na}$ época, em função da falta de dados analíticos confiáveis de fibra alimentar, os mesmos problemas da América Latina, sobre avaliação da ingestão de fibra e carboidratos, existiam no Brasil. Nesse sentido, nosso grupo passou a direcionar esforços para a obtenção de dados analíticos de fibra alimentar, amido resistente e de outros nutrientes em alimentos brasileiros.

Em 1998, foi criada pela Faculdade de Ciências Farmacêuticas da Universidade de São Paulo (FCF/USP) e Rede Brasileira de Dados de Composição de Alimentos (BRASILFOODS) a primeira versão da Tabela Brasileira de Composição de Alimentos (TBCA-USP), a qual foi disponibilizada pela internet (http://www.fcf.usp.br/tabela) (USP, 1998, Anexo 3). Esta base de dados foi estruturada de acordo com as normas internacionais propostas pelo International Network of Food Data Systems (INFOODS), visando a integração e validação dos dados brasileiros no contexto nacional e mundial. Todos os dados de amido resistente foram obtidos através de análise efetuadas no Laboratório de Química, Bioquímica e Biologia Molecular da FCF da USP, sob minha coordenação. Com relação aos dados de fibra alimentar, a maior parte foi analisada nos diversos laboratórios da FCF, através de métodos enzímicogravimétrico ou químico. Dados dos demais nutrientes foram compilados de publicações nacionais e de dados ínternos de laboratórios. Lembrando que para inclusão de qualquer tipo de informação no banco de dados, independentemente da sua procedência, todos os dados passaram por criteriosa avaliação.

O controle de qualidade de uma análise laboratorial é essencial para garantir a confiabilidade da informação. Os resultados analíticos são considerados de aplicação restrita se não houver um programa definido de controle de qualidade (GREENFIELD; SOUTHGATE, 2003). A adoção de adequados critérios de qualidade analítica visa a conscientização dos diversos profissionais que atuam na área, sendo de importância para a compilação correta dos dados (compilador), para a análise precisa do nutriente (analista) e para a interpretação correta dos dados (usuário).

Para a realização da compilação dos dados nacionais de fibra alimentar, foram criados modelos esquemáticos para avaliação da qualidade analítica 
destas informações (CARUSO; LAJOLO; MENEZES, 1999, Anexo 4). Os critérios do U.S. Department of Agriculture (USDA), ernpregados na avaliação de selênio (BIGWOOD et al.,1987; HOLDEN et al., 1987) e de carotenóides (MANGELS et al., 1993), foram adaptados para a fibra alimentar.

Esses modelos foram, a seguir, ampliados e publicados em revista de impacto internacional (MENEZES; CARUSO; LAJOLO, 2000, Anexo 5). Os dados sobre conteúdo de FA dos alimentos foram avaliados através de questões padronizadas desenvolvidas para as seguintes categorias: número de amostras; plano de amostragem; manuseio das amostras; método analítico e controle de qualidade analítica. A partir destas categorias, foi estabelecido um código de confiança para que os dados de alimentos brasileiros pudessem ser avaliados. O código de confiança obtido para 180 alimentos foram $29 \%$ com códigos $A$ e $B$ (confiança considerável e razoável) e $71 \%$ com código $C$ (confiança reduzida). Entretanto, não foi possível estabelecer o código de confiança para 244 alimentos compilados devido à metodologia inadequada utilizada. A avaliação da qualidade de dados de FA permitiu acesso a dados atualizados e confiáveis, além da identificação dos alimentos prioritários para análise. Os dados de FA avaliados foram, então, incluídos na TBCA-USP (http://www.fcf.usp.br/tabela), possibilitando a estimativa da ingestão de fibra alimentar pela população.

No futuro, é esperado um aumento no número de dados considerados aceitáveis, baseado na realização de análises que levem em conta a ampla gama de fatores que interferem na qualidade do resultado. Ao mesmo tempo, existe a necessidade de conscientização dos pesquisadores sobre a importância de adequados procedimentos analíticos e sua criteriosa descrição e documentação durante a publicação (CARUSO; LAJOLO; MENEZES, 1999, Anexo 4; MENEZES; CARUSO; LAJOLO, 2000, Anexo 5; MENEZES; CARUSO; LAJOLO, 2001).

A partir da disseminação, pela TBCA-USP (USP, 1998, Anexo 3), de informações precisas sobre o conteúdo de FA e de amido resistente em alimentos brasileiros, tínhamos condições de estimar a ingestão destes componentes pela população.

Em dois capitulos de livros internacionais, em 2001, foi publicada a estimativa de ingestão média de fibra alimentar (FA) e amido resistente (AR) 
pela população brasileira (LAJOLO; MENEZES, 2001, Anexo 6 e MENEZES; GIUNTINI; LAJOLO, 2001, Anexo 7). Essa estimativa foi calculada com base nos dados de aquisição de alimentos contidos nas pesquisas da Fundação Instituto Brasileiro de Geografia e Estatística de seis regiões metropolitanas em três décadas. Na década de 70, a ingestão média de fibra alimentar (FA) era de $19,3 \mathrm{~g} / \mathrm{dia}$, caindo para $16,0 \mathrm{~g} / \mathrm{dia}$ na década de 80 e chegando a 12,4g/dia na década de 90. Segundo as recomendações nutricionais propostas para a população brasileira (mínimo 20g/dia para jovens e adultos), pudemos observar que durante a década de 70, a ingestão estava praticamente adequada em relação ao mínimo indicado, passando para $80 \%$ e $62 \%$ de adequação nas décadas seguintes. Essa inadequação é preocupante considerando os benéficos efeitos fisiológicos decorrentes da ingestão habitual de fibra alimentar na prevenção de inúmeras DCNT. Essas mudanças tendem a se acentuar em função da globalização da economia, e estão tornando a dieta tipicamente brasileira muito parecida com a alimentação dos países desenvolvidos. A ingestão média estimada de AR sofreu redução ao longo das três décadas; na década de 70 era de $5,0 \mathrm{~g} / \mathrm{dia}$ e passou para $3,4 \mathrm{~g} / \mathrm{dia}$ na década de 90. Essa evolução acompanhou uma redução de ingestão de carboidratos totais que foi ao redor de $26 \%$. A ingestão de AR, no Brasil, assemelha-se ao encontrado na Europa $(3,2 \mathrm{~g} / \mathrm{dia})$. Considerando que o AR pode ter um papel complementar ao da fibra alimentar para a prevenção de determinadas doenças crônicas não-transmissíveis, a ingestão deste componente poderia ser estimulada.

Em função da necessidade de informações analíticas de qualidade sobre fibra alimentar (FA) e amido resistente (AR) em diversos países, uma das metas do projeto de cooperação internacional CYTED/CNPq XI.6 era a criação de um banco de dados destes componentes. Nesse sentido, elaboramos e publicamos um banco ibero-americano sobre o conteúdo de FA e AR de alimentos tradicionais, além de outras possíveis fontes (MENEZES; LAJOLO, 2000, Anexo 8). Paralelamente, para facilitar a disseminação destas informações, este banco de dados foi disponibilizado na internet (http://www.fcf.usp.br/cytedxi6) (USP, 2000).

O livro "Contenido en fibra dietética y almidón resistente en alimentos y productos iberoamericanos" (MENEZES; LAJOLO, 2000, Anexo 8) contém 
informações provenientes de nove países ibero-americanos, sobre a concentração de fibra alimentar e amido resistente de alimentos, fontes potenciais (resíduos industriais e alimentos não-convencionais) e produtos. Os dados foram compilados adotando as normas do International Network of Food Data Systems (INFOODS) e Red Latinoamericana de Datos de Composición de Alimentos (LATINFOODS) e engloba 817 dados de fibra alimentar (cereais e derivados - 223; vegetais e derivados - 305; frutas e derivados - 147; alimentos $\mathrm{p} /$ regimes especiais -67 ; alimentos industrializados - 51 ; alimentos preparados - 24). Para o amido resistente foram compilados 207 dados (cereais e derivados - 65; vegetais e derivados - 126; frutas e derivados - 16). Este livro oferece informações para facilitar a avaliação da ingestão de fibra alimentar individual ou por populações, bem como orientar o consumidor na seleção de alimentos fontes de fibra alimentar.

Nesse contexto, o potencial das fontes ibero-americanas de fibra alimentar e amido resistente foi relatado e publicado nos Archivos Latinoamericanos de Nutrición (GIUNTINI; MENEZES; LAJOLO, 2003, Anexo 9). Nos últimos anos, muitos pesquisadores de países ibero-americanos vêm quantificando e caracterizando adequadamente a FA em alimentos e em resíduos industriais, buscando tecnologia para produzir concentrados, desenvolvendo e testando produtos enriquecidos a partir de alimentos regionais. Existe grande disponibilidade de alimentos regionais e tradicionais com conteúdo significativo de fibra alimentar como frutas, hortaliças e, principalmente, cereais e leguminosas. Fontes concentradas de FA, obtidas a partir de diferentes resíduos industriais, foram caracterizadas e avaliadas, podendo ser utilizadas no enriquecimento de alimentos. Alguns produtos enriquecidos vêm sendo testados, como biscoitos com torta de milho na Colômbia (produto contendo $16,8 \%$ de FA na base integral) e macarrão com fibra de tremoço no Chile $(11,2 \%)$. No mercado cubano, encontram-se produtos como pão de trigo integral (12\%); produtos para fins especiais, como comprimidos de fibra de cítricos (55\%), e alimentos para dieta enteral $(1-1,9 \%)$. $\mathrm{Na}$ Espariha, existem patentes depositadas de concentrados de FA (maracujá). As informações sinalizam para o significativo potencial de FA nos países iberoamericanos, o qual pode auxiliar no aumento da ingestão alimentar deste componente. 
Em decorrência da produção de inúmeras publicações e atividades de pesquisa relacionadas à fibra alimentar, participei da coordenação da publicação do livro "Fibra dietética en Iberoamérica: Tecnología y salud. Obtención, caracterización, efecto fisiológico y aplicación en alimentos" (LAJOLO et al., 2001, Anexo 10). A temática da fibra alimentar é discutida de forma ampla em 34 capítulos revisados por pesquisadores especializados. Muitas informações ibero-americanas não disponíveis em publicações internacionais foram incluidas neste livro, que engloba desde aspectos analíticos e de caracterização molecular dos polissacarídeos até as propriedades físico-químicas da FA, as quais são responsáveis por inúmeros efeitos fisiológicos com conseqüências para a saúde.

O Prof. Lajolo e eu coordenamos outro livro internacional "Carbohidratos en alimentos regionales iberoamericanos" editado pela EDUSP, em 2006 (LAJOLO; MENEZES, 2006, Anexo 11). Este livro contém informações sobre carboidratos de alimentos regionais ibero-americanos e integra, em uma publicação em espanhol e português, conhecimentos químicos, tecnológicos e fisiológicos de utilidade para o desenvolvimento de investigações nesta temática, e oferece material de utilidade tanto para pesquisa como para fins didáticos, podendo ser útil para organismos privados, entidades governamentais e universidades. A publicação contém 26 capítulos revisados por pesquisadores especializados e inclui temas que abordam desde metodologia analítica, caracterização estrutural e propriedades físico-químicas, até aspectos clínicos e epidemiológicos da ingestão de carboidratos. Trata-se de um dos produtos do projeto de cooperação internacional CYTED XI.18/ CNPq "Composición, Estructura, Propiedades Biológicas de Carbohidratos y su Utilización en Alimentos", onde especialistas, participantes do projeto e outros pesquisadores realizaram revisões bastante detalhas sobre o tema.

A forma de disponibilizar os dados de carboidratos nas tabelas de composição de alimentos não está de acordo com as necessidades dos usuários, e nem acompanha as descobertas sobre os efeitos fisiológicos destes componentes sobre a prevenção de doenças crônicas não-transmissíveis (GREENFIELD; SOUTHGATE, 2003; ENGLYST; LIU; ENGLYST, 2007; MANN et al., 2007). Na maior parte das tabelas, os carboidratos são calculados por diferença, isto é: [100 - (conteúdo de umidade + proteínas + lipídios + cinzas + 
fibra alimentar)], o que pode gerar erros e não proporciona uma estimativa exata. A tendência mundial é que as tabelas de composição incluam os carboidratos analisados individualmente, pois cada tipo de carboidrato tem diferente função fisiológica no organismo humano, além da informação sobre o conteúdo dos carboidratos totais ser mais precisa (MONRO; BURLINGAME, 1996; LI; ANDREWS; PEHRSSON, 2002).

Para tentar solucionar este problema, o grupo vem realizando análises de carboidratos, de forma individual, em uma série de alimentos brasileiros (CORDENUNSI et al., 2000; ROSIN; LAJOLO; MENEZES, 2002, Anexo 12; MENEZES et al., 2004, Anexo 13; SOUZA, 2005; CARDENETTE, 2006; MENEZES, 2006; MENEZES, 2007b), e compilando informações de outros laboratórios, visando substituir os dados de carboidratos da TBCA-USP, estimados por diferença, por informação específica de cada tipo de carboidrato presente nos alimentos. Em duas publicações (ROSIN; LAJOLO; MENEZES, 2002, Anexo 12 e MENEZES et al., 2004, Anexo 13) foram quantificados o conteúdo das diferentes frações de amido (amido total, disponivel e resistente), fibra alimentar, amilose, açúcares solúveis (glicose, frutose e sacarose) e as frações não-disponíveis de carboidratos (total, solúvel e insolúvel) de onze alimentos fontes de amido usualmente consumidos pela população brasileira. Paralelamente, foi estudado o perfil de hidrólise in vitro de cada alimento, bem como a influência da análise individual dos diferentes carboidratos sobre o valor energético. Ao mesmo tempo, outras informações de alimentos brasileiros, provenientes de publicações e/ou de outros laboratórios da USP, estão sendo compiladas para a criação de um banco de dados de carboidratos, com os diferentes componentes individualmente analisados de acordo com o perfil do alimento.

A fibra alimentar faz parte do grupo dos carboidratos, e sua definição vem sendo discutida desde a década de 70 , sem que exista um consenso; o mesmo ocorre com os métodos analíticos para sua quantificação (GRAY, 2006; MANN et al., 2007; CUMMINGS; STEPHEN, 2007; ENGLYST; LIU; ENGLYST, 2007).

O grupo vem contribuindo de forma significativa para disseminar informações sobre fibra alimentar, escrevendo inúmeros capítulos e livros, desde 1988 (LAJOLO; MENEZES; FILISETTI-COZZI, 1988a, Anexo 1; 
LAJOLO et al., 2001, Anexo 10; LAJOLO; MENEZES, 2001, Anexo 6; LAJOLO; FILISETTI-COZZI; MENEZES, 1991; LAJOLO; MENEZES, 2006, Anexo 11; MENEZES, 2007b; MENEZES; GIUNTINI (no prelo). Este último capítulo foi aceito para publicação na $2^{\mathrm{a}}$ edição do livro Ciências Nutricionais dos professores Dutra-de-Oliveira e Marchini. Ao mesmo tempo, o grupo tem participado das discussões nacionais sobre a definição de fibra alimentar junto ao CODEX.

As informações relatadas nesta parte do documento visaram elucidar qual é a ingestão de fibra alimentar e de amido resistente, principais representantes dos carboidratos não-disponíveis, pela população brasileira e todas as atividades envolvidas e necessárias para se atingir essa meta. Até a década de 90 , este questionamento foi respondido e relatado nas publicações citadas. Cabe, agora, responder para a década atual. A recente publicação do capítulo "Fibra alimentar" (MENEZES; GIUNTINI, 2008, Anexo 14) descreve essa informação, além de incluir detalhada revisão sobre fibra alimentar.

Nesse trabalho, a estimativa de ingestão atual de FA e AR foi projetada sobre os dados de aquisição de alimentos da Pesquisa de Orçamento Familiar - POF 2002/2003 (IBGE, 2004). Em 2002/2003 a ingestão média de FA pela população brasileira foi da ordem de $15,39 \mathrm{~g} / \mathrm{dia}$, sendo $5,94 \mathrm{~g} / \mathrm{dia}$ proveniente de cereais e tubérculos, 7,53g/dia de leguminosas, 0,98g/dia de hortaliças e $1,23 \mathrm{~g} / \mathrm{dia}$ de frutas. As leguminosas, principalmente o feijão, representam a mais alta proporção quanto ao fornecimento de FA da dieta na maior parte dos estados, com exceção do estado do Pará, onde a farinha de mandioca, alta fonte de FA, é muito consumida. O consumo de frutas e hortaliças, alimentos considerados tradicionalmente fontes de FA, é extremamente baixo. Assim sendo, a ingestão de FA pela população brasileira pode ser indiretamente avaliada através do consumo de feijão, arroz polido e pão francês, embora estes dois últimos não sejam fontes expressivas, são consumidos em todos os estados em quantidades significativas.

A ingestão média de AR foi de 3,7g/dia em 2002/2003. O feijão, arroz e pão francês representam novamente as maiores fontes de AR em todas as regiões, mas alguns alimentos regionais contribuem de forma importante; por exemplo, o fubá (milho) é mais consurnido nas regiões Nordeste e Sudeste (principalmente no estado de Pernambuco); a farinha de mandioca tem 
consumo elevado na região Norte; o biscoito e macarrão são consumidos em todas regiões, embora em pequenas quantidades.

Avaliando a ingestão intrafamiliar, podemos observar que, durante a década de 70 , a ingestão de FA representava $77 \%$ da meta de ingestão minima recomendada, que é de $25 \mathrm{~g} /$ dia (FAO; WHO, 2003), passando para $64 \%$ nos anos $80,50 \%$ nos anos 90 e $61 \%$ na década atual. Para o AR, não existem recomendações específicas. O reduzido consumo de alimentos fontes de FA e AR observado junto à população brasileira é preocupante, considerando os benéficos efeitos fisiológicos decorrentes da adequada ingestão desses componentes e de compostos associados à fibra alimentar na prevenção de inúmeras doenças crônicas não-transmissíveis.

Programas de orientação nutricional e reeducação alimentar, voltados para a população brasileira, são necessários e devem estimular a manutenção de certos hábitos alimentares praticados pela população em décadas anteriores, como o consumo de arroz e feijão e consumo de alimentos contendo carboidratos não-disponíveis, como as frutas e hortaliças. Esses alimentos irão contribuir tanto para a ingestão de quantidades adequadas de FA, AR e de outros nutrientes, como também para diversificar o tipo de fibra alimentar ingerida, a qual pode estar associada a compostos bioativos como os fenólicos e outros. Alternativamente, a produção de alimentos funcionais para necessidades específicas pode também ser interessante.

\subsection{Aproveitamento de carboidratos de alimentos: estudos in vitro e} in vivo

Os primeiros estudos sobre o efeito fisiológico do inibidor de alfa-amilase isolado do feijão preto Rico 23 (Phaseolus vulgaris L) foram realizados por Lajolo (1977), nos laboratórios da FCF- USP. Dando prosseguimento aos estudos deste inibidor, Menezes e o grupo publicaram diversos trabalhos que envolviam estudos com animais, tanto em ratos saudáveis como diabéticos (LAJOLO; MANCINI-FILHO; MENEZES, 1984; MENEZES; LAJOLO, 1987; LAJOLO; FINARDI-FILHO; MENEZES, 1991). Os resultados mostraram que este inibidor tem a capacidade de reduzir a digestão do amido cru, a qual é dose-dependente; reduzir os níveis séricos pós-prandiais de glicose e insulina; aumentar a metabolização de ácidos graxos não-esterificados do tecido 
adiposo e não estimular a secreção pancreática de alfa-amilase para o intestino delgado. Alguns destes efeitos também foram observados, e ainda mais pronunciados, em ratos diabéticos. Estes estudos com o inibidor de alfa amilase possibilitaram a implantação de inúmeras técnicas para avaliação do aproveitamento biológico de carboidrato não-disponível e mostravam, já na época, o interesse do grupo em estudar alternativas alimentares relacionadas com o aproveitamento de carboidratos.

Visando a prevenção das doenças crônicas não-transmissíveis (DCNT), tem sido enfatizada a importância dos efeitos benéficos proporcionados pelas dietas (WHO; FAO, 2003). Com a redução da excessiva ingestão de lipídios, ocorre o aumento da ingestão de carboidratos, cuja qualidade deve ser considerada. A composição química é um importante parâmetro na seleção dos alimentos (USP, 1998, Anexo 3); entretanto, o simples conhecimento da composição dos carboidratos não reflete precisamente seu aproveitamento no organismo e seus efeitos fisiológicos.

O processo de digestão dos carboidratos envolve uma série de fases, que vão desde a mastigação, esvaziamento gástrico, digestão, absorção pelos enterócitos do intestino delgado até a penetração dos monômeros na corrente sangüínea, processo que resulta na alteração dos níveis de glicose plasmática. Elevados níveis plasmáticos de insulina e a resistência à insulina, assim como outros determinantes (ingestão de dietas com elevado aporte energético, obesidade, falta de atividade física), estão envolvidos na etiologia de diabetes, doenças cardiovasculares e câncer. A partir das observações de que os carboidratos de diferentes fontes são digeridos e absorvidos de forma diferenciada, a velocidade de digestão pode ser considerada um relevante critério para a avaliação do aproveitamento dos carboidratos (FAO; WHO, 1998). Assim, os carboidratos podem ser classificados em carboidratos de lenta digestão e carboidratos de rápida digestão (ENGLYST et al., 2003; ENGLYST, LIU; ENGLYST, 2007). Os carboidratos de lenta digestão proporcionam moderado aumento de glicose e insulina plasmática após refeição com elevada quantidade de carboidrato e permitem a prolongada entrada de glicose na corrente sangüínea (DANONE VITAPOLE; FAO, 2001; FAO; WHO, 2003; VENN; GREEN, 2007). Alimentos que contêm carboidratos de lenta digestão têm mostrado eficácia no controle da saciedade, da 
resistência à insulina e dos níveis plasmáticos de glicose, insulina e lipídios. Como é impossivel determinar diretamente as características nutricionais dos carboidratos que são de lenta ou rápida digestão, foram criados marcadores apropriados, como o índice glicêmico (IG) e a carga glicêmica (CG).

O IG, que foi introduzido em 1981 (JENKINS et al., 1981), diferencia os carboidratos dos alimentos (25 ou $50 \mathrm{~g}$ de carboidrato disponível) com base no seu potencial em aumentar a resposta glicêmica em relação aos carboidratos de um alimento controle. O conceito de carga glicêmica (CG) foi proposto em 1997 (SALMERON et al., 1997). Este marcador mede o impacto glicêmico da dieta e é calculado pela multiplicação do IG do alimento pela quantidade de carboidrato disponível contida na porção consumida deste alimento. A dieta com baixo IG e baixa CG tem efeitos benéficos sobre vários aspectos metabólicos e fisiológicos envolvidos nas DCNT (FAO; WHO, 1998; AUGUSTIN et al., 2002; BRAND-MILLER, 2003; LUDWIG, 2003; VENN; GREEN, 2007; MANN, 2007), e grande parte destes efeitos pode ser extrapolada para as dietas com carboidratos de lenta digestão, uma vez que os alimentos de baixo IG geralmente contêm elevado conteúdo desta fração. Algumas formas de amido são pouco digeridas pelo organismo humano; outras, inclusive, não são digeridas no intestino delgado (caso do amido resistente). No intestino grosso, esses carboidratos são fermentados, resultando na produção de vários compostos, sendo os ácidos graxos de cadeia curta em maior proporção. Tais compostos, além de fornecerem energia, estão envolvidos na prevenção e controle de DCNT (FAO; WHO, 1998; WHO; FAO, 2003; ELIA; CUMMINGS, 2007). As diferentes respostas glicêmicas produzidas pelos alimentos são decorrentes da presença de determinados fatores intrínsecos e extrínsecos dos alimentos, que interferem na digestão e absorção do amido. O conhecimento da presença destes fatores é de importância para a manutenção de reduzidos IGs produzidos por certos alimentos (BJÖRCK, 1996; FAO; WHO, 1998; MENEZES, 2000a). A partir de informações provenientes de uma ampla variedade de estudos, foram criadas tabelas com o IG produzido por alimentos de diferentes partes do mundo e em diversas condições fisiológicas (FOSTER-POWELL; BRAND-MILLER, 1995; FOSTER-POWELL; HOLT; BRAND-MILLER, 2002; SYDNEY UNIVERSITY GLYCEMIC INDEX RESEARCH SERVICE, 2007). 
Os componentes da dieta, que não são digeridos por enzimas intestinais e nem absorvidos no intestino delgado, chegam ao intestino grosso, onde podem ser degradados pela microbiota ali presente. Este processo denominase fermentação colônica, e consiste na degradação anaeróbia de substratos, principalmente carboidratos, pela microbiota intestinal (GOÑI; MARTíNCARRÓN, 2001).

A fração não-disponível da dieta, além de uma porção considerável de mucina, células epiteliais, enzimas e outros produtos de origem endógena são substratos utilizados pelas bactérias colônicas humanas na fermentação (CUMMINGS; MACFARLANE, 1991; ELIA; CUMIMINGS, 2007). A fração nãodisponível é composta, em sua maior parte, de amido resistente, fibra alimentar, proteína resistente, oligossacarídeos, lipídios, polifenóis e outros componentes associados (SAURA-CALIXTO et al., 2000; GOÑI; MARTINCARRÓN, 2001).

O conceito de prebióticos está relacionado com os carboidratos nãodisponíveis. Em 1995, os prebióticos foram definidos como ingredientes nãodisponíveis de alimentos que afetam beneficamente $o$ hospedeiro por estimulação seletiva de crescimento e/ou atividade de uma ou um número limitado de bactérias no cólon, melhorando a saúde do hospedeiro (GIBSON; ROBERFROID, 1995). Em 2004, Gibson propôs uma definição mais rígida para a caracterização de ingredientes ou componentes alimentares como sendo prebióticos (GIBSON et al., 2004). Segundo proposto, para uma substância ser considerada um prebiótico, deve haver demonstração científica de que o componente ou ingrediente alimentar resista aos processos de digestão, absorção e adsorção do hospedeiro, que seja fermentado pela microbiota, colonizando o trato gastrintestinal, e estimule o crescimento e/ou atividade de uma ou de um número limitado de bactérias dentro do trato gastrintestinal. As demonstrações finais devem ser realizadas in vivo, seja em animais ou humanos. Em 2007, foi proposta a inclusão do uso do índice prebiótico na caracterização de prebiótico, que foi definido como o aumento absoluto do número de bifidobactérias dividido pela dose diária do prebiótico ingerido (ROBERFROID, 2007).

Entretanto, nem todos os carboidratos não-disponiveis e fermentáveis podem ser considerados prebióticos (GIBSON et al., 2004); somente a inulina, 
transgalactooligossacarídeo e lactulose atendem todos os critérios de classificação (ROBERFROID, 2007). A polidextrose e o amido resistente, por exemplo, estão sendo estudados para verificar seu possível efeito prebiótico, principalmente no que se refere aos seus efeitos benéficos no intestino grosso (GIBSON et al., 2004; LEAL, 2005).

A fermentação colônica tem importantes repercussões sobre a saúde do hospedeiro. Alguns metabólitos da microbiota são substâncias tóxicas para o organismo (amoníaco, aminas e nitrosaminas carcinógenas); outros podem reduzir a biodisponibilidade de vitaminas e minerais. Entretanto, o aumento da massa bacteriana e os ácidos graxos de cadeia curta (AGCC) (acetato, propionato e butirato) trazem benefícios para o organismo, e se relacionam com a etiologia e prevenção de diferentes DCNT de grande incidência na atualidade, como é o caso do câncer de cólon e doenças cardiovasculares (VELÁZQUEZ; LEDERER; ROMBEAU, 1996; WHO; FAO, 2003; ELIA; CUMNINGS, 2007; KEY; SPENCER, 2007; MANN, 2007).

De acordo com essas tendências mundiais relatadas sobre o estudo do aproveitamento biológico dos carboidratos, o grupo realizou uma série de estudos com diferentes alimentos brasileiros fontes de carboidratos nãodisponíveis, enfocando desde a resposta glicêmica produzida até os efeitos da fermentação dos carboidratos não-disponíveis no intestino grosso, sempre visando avaliar o potencial destes alimentos como ingrediente funcional. Alguns destes estudos estão relatados a seguir.

Primeiramente, foram avaliadas as respostas glicêmicas produzidas pela ingestão de diferentes alimentos de consumo habitual da população brasileira e seus possíveis efeitos metabólicos e fisiológicos, sendo realizados ensaios com animais, humanos e in vitro. Também foram estudados os mecanismos envolvidos no reduzido aproveitamento do amido do feijão, visando sua preservação no processamento dos alimentos (MIENEZES; LAJOLO, 1995, Anexo 15; MENEZES et al.,1996, Anexo 16 e MENEZES; LAJOLO, 1997, Anexo 17).

Em ensaios de curta duração com animais, a resposta glicêmica produzida após a ingestão de polenta, pão de forma ou arroz branco foi significantemente diferente da resposta do feijão (Carioca e Fradinho) e farelo de trigo $(p<0,05)$ (reduzida). Para o milho extrusado, pão branco, curau, batata, 
farinha de milho, beiju, macarrão, canjica, farinha de mandioca crua e mandioca, a resposta glicêmica foi similar (elevada). Em humanos, o feijão com e sem casca produziu respostas glicêrnicas significantemente menores se comparadas com as respostas da polenta, arroz e arroz com feijão. O mesmo ocorreu com os níveis plasmáticos de insulina. A secreção de GLP-1 7-36 foi a mesma para polenta ou feijão. A casca do feijão não teve influência sobre as respostas plasmáticas de glicose $e$ insulina. A correlação positiva entre digestibilidade in vitro e resposta glicêmica em animais $(y=721+3,7 x ; r=0,824$, $p<0,01)$ e em humanos $(y=787+3,9 x ; r=0,935, p<0,01)$ permite o uso da técnica in vitro para seleção preliminar de alimentos fontes de amido (MENEZES et al., 1996, Anexo 16).

Em ensaios de média duração com ratos, foram estudados os efeitos fisiológicos produzidos pela ingestão do feijão e a participação da microbiota intestinal na sua utilização. O experimento foi constituído de duas fases: adaptação (8 dias) e experimental (31 dias). Durante a fase experimental, os animais foram divididos em quatro grupos e receberam rações isoenergéticas à base de polenta (controle) ou feijão, com adição ou não de antibiótico. A atividade das dissacaridases intestinais (maltase e invertase) foi semelhante para os dois alimentos estudados. Os animais do grupo feijão tiveram menor ganho de peso, menor peso da carcaça, maior excreção fecal e redução nos níveis plasmáticos de colesterol total, triacilgliceróis e LDL-colesterol em relação ao grupo polenta. Estes resultados evidenciaram, mesmo após a prolongada ingestão da ração com feijão, a persistência do menor aproveitamento energético de seu amido. Os efeitos foram minimizados na presença do antibiótico, demonstrando a importância da fermentação da fibra alimentar e amido resistente do feijão no perfil de lipídios plasmáticos e na utilização energética (MENEZES; LAJOLO, 1997, Anexo 17).

Com relação aos possiveis fatores que proporcionam o menor aproveitamento do amido da semente de feijão, foi demonstrado que: a) a integridade da parede celular atua como uma barreira física que dificulta o entumecimento e a completa gelatinização dos grânulos de amido, e a ação das enzimas hidrolíticas sobre o amido; b) a organização física entre os grânulos de amido e as proteínas do feijäo interfere, parcialmente, no aproveitamento do amido; c) os compostos presentes na casca (fenólicos e 
outros) ou na parede celular (fibra alimentar), quando isolados e novamente adicionados ao amido isolado de feijão, não interferem no aproveitamento do amido. Estes resultados evidenciaram a necessidade da integridade da parede celular para garantir o reduzido aproveitamento do amido do feijão cozido (MENEZES; LAJOLO, 1995, Anexo 15).

Em outro estudo, foi avaliada a resposta glicêmica produzida em ratos, após a ingestão de 21 alimentos de consumo habitual da população, sendo as leguminosas (feijão, lentilha, grão de bico e ervilha) os alimentos com menor IG (40-50\%) (MENEZES; LAJOLO, 2003, Anexo 18)

A influência do armazenamento de alimentos fonte de amido, sob baixa temperatura $\left(-20^{\circ} \mathrm{C} / 30\right.$ dias), e a formação de amido resistente sobre o índice glicêmico (IG) dos alimentos também foi estudada (CARREIRA; LAJOLO; MENEZES, 2004, Anexo 19). Foi observado um aumento significante no conteúdo de amido resistente em todos os alimentos armazenados. O armazenamento resultou em uma diminuição significante no IG do feijão e grão de bico; o IG do macarrão continuou o mesmo e o IG da polenta aumentou. Dessa forma, a formação de AR apresenta reduzida influência sobre o IG. O armazenamento de alimentos fontes de amido sob baixa temperatura pode colaborar para a ingestão de AR, porém seu efeito sobre o IG dependerá das características dos carboidratos de cada alimento.

Com a finalidade de delinear os possiveis fatores que interferem na digestibilidade dos carboidratos, bem como definir métodos in vitro que sirvam para estimar a resposta glicêmica a ser produzida pelos alimentos, os resultados de diferentes parâmetros previamente publicados pelo grupo foram correlacionados (MENEZES; LAJOLO, 2006, Anexo 20). Entre os parâmetros avaliados estão a resposta glicêmica pós-prandial produzida por cada alimento; formação de amido resistente e conteúdo de amido resistente, amido total, amido de lenta digestão (ARD), fibra alimentar e amilose. O conteúdo de ARD foi quantificado após 30min de incubação enzimática (GOÑl; GARCÍAALONSO; SAURA-CALIXTO, 1997). Entre as publicações envolvidas estão os anexos 12, 16 ,18 e 19 (ROSIN; LAJOLO; MENEZES, 2002, Anexo 12, MENEZES et al.,1996, Anexo 16, MENEZES; LAJOLO, 2003, Anexo 18; CARREIRA; LAJOLO; MENEZES, 2004, Anexo 19). 
Com base nos resultados das principais correlações foi possível concluir que, para os alimentos estudados, o conteúdo de amido total, amido resistente, fibra alimentar total ou amilose (o qual está envolvido na formação de amido resistente) não representam bons parâmetros para prever a resposta glicêmica produzida pela ingestão dos alimentos (MENEZES; LAJOLO, 2006, Anexo 20). Por outro lado, nessa publicação pode ser visualizada a correlação entre o IG dos alimentos avaliados em humanos e animais e o conteúdo de amido de rápida digestão ( $A R D$ ) (\% base seca). Estes resultados mostraram significativa correlação positiva entre valores de IG em humanos (CARREIRA; LAJOLO; MENEZES, 2004, Anexo 19) e conteúdo de ARD (ROSIN; LAJOLO; MENEZES, 2002, Anexo 12) de nove alimentos (\% base seca) $(y=1,97 x$ $+0,76 ; r=0,893 ; p \leq 0,001 ; n=9)$. Paralelamente, também pôde ser observada significativa correlação positiva entre valores de IG em animais e ARD de 31 alimentos ( $y=2,190 x+5,21 ; r=0,776 ; p \leq 0,001 ; n=31)$. Assim, pôde-se concluir que $\circ$ tipo de alimento e seu processamento estão diretamente relacionados tanto com o IG como com o conteúdo de ARD, expresso na base seca. O pão branco é um exemplo de alimento altamente processado; o seu amido é totalmente gelatinizado, o que possibilita sua rápida digestão e produção de alto IG. Paralelamente, o pão tem valores elevados de ARD. Nas leguminosas e nos grãos de cereais pouco processados, o amido está encapsulado pela parede celular, o que retarda a sua digestão e absorção; por isso, estes alimentos têm valores baixos de ARD. Dessa forma, o conteúdo de amido de rápida digestão, expresso na base seca, representa um marcador que reflete as respostas glicêmicas que os alimentos irão produzir, podendo ser utilizado para a triagem preliminar de alimentos fontes de amido.

A resposta glicêmica produzida pela ingestão de pinhão (Araucaria angustifolia) cozido com e sem casca foi avaliada em voluntários saudáveis, assim como a composição química e conteúdo de compostos bioativos (CORDENUNSI et al., 2004, Anexo 21). A presença da casca durante a cocção do pinhão não interferiu no aproveitamento de seu amido, sendo classificado como alimento de baixo índice glicêmico. As sementes cozidas em condições normais (com a casca) apresentaram conteúdo de fenólicos totais cinco vezes maior do que as sementes cozidas sem casca, desta forma, o processo de cocção mostrou-se extremamente favorável para o conteúdo de 
compostos bioativos das sementes de pinhão. As informações sobre as diferentes frações de carboidratos do pinhão e sua resposta glicêmica irão compor o banco de dados de carboidratos que está sendo elaborado pela TBCA-USP e BRASILFOODS.

Em função dos diversos estudos realizados pelo grupo referentes à resposta glicêmica de alimentos brasileiros e elucidação de fatores que interferem na digestibilidade do amido, o grupo foi convidado para participar de inúmeros eventos internacionais e nacionais, visando a disseminação de resultados científicos. Pode ser ressaltada a participação do grupo, em 2001, na elaboração do "Consensual Statement from the International Workshop Glycaemic Index and Health, The Quality of the Evidence" (DANONE VITAPOLE; FAO, 2001), quando participei do evento e da elaboração do documento (conforme mencionado na pg. 45 da publicação).

Ao mesmo tempo, escrevemos algumas revisões sobre índice glicêmico (IG) que foram publicadas em anais completos de eventos e periódicos, que abordam: definição; problemas relacionados com a metodologia empregada na determinação; os fatores que interferem na digestão e absorção de carboidratos; IG de alimentos; IG e as tabelas de composição de alimentos; aplicação do IG na prática clínica e IG na prevenção de DCNT. Em todas essas oportunidades exemplificamos com resultados em alimentos nacionais (CARUSO; MENEZES, 2000; MENEZES, 2000a; MENEZES, 2000b).

A elaboração de um banco de dados de resposta glicêmica de alimentos brasileiros faz parte de uma das metas de pesquisa do grupo. Neste sentido, diversos alimentos vêm sendo testados como parte de projetos de pesquisa (SOUZA, 2005; CARDENETTE, 2006; DAN, 2007) ou mesmo em parcerias com indústrias de alimentos para o financiamento destes ensaios (MENEZES, 2006; MENEZES, 2007b). Um bom exemplo refere-se à resposta glicêmica produzida pela ingestão de pães. Cerca de 18 diferentes tipos de pães de diversas empresas estão sendo testados, sendo que parte já tem seu indice glicêmico e carga glicêmica calculados. Todas as empresas já autorizaram a disseminação dessas informações na TBCA-USP (http://www.fcf.usp.br/tabela). Ao mesmo tempo, para qualquer avaliação de resposta glicêmica, o perfil de carboidratos do alimento é analisado, para cálculo da quantidade de 
carboidrato disponível a ser ingerido, e estas informações também estão sendo incorporadas ao banco de dados.

Em resumo, este banco de dados está sendo criado com parte das informações produzidas pelo grupo e outras estão sendo compiladas de publicações e de informações de outros laboratórios da USP, principalmente sobre o conteúdo individual de carboidratos. A versão preliminar deste banco de dados sobre carboidratos e resposta glicêmica de alimentos brasileiros, a ser incluído na TBCA-USP/BRASILFOODS, foi apresentada durante a $7^{\text {th }}$ International Food Data Conference (MENEZES et al., 2007, Anexo 22).

Os principais carboidratos não-disponíveis (fibra alimentar ou polissacarídeos não-amido, amido resistente e oligossacarídeos) não são os determinantes da produção de reduzidos IGs per se. Entretanto, muitos alimentos produtores de reduzida elevação da glicemia pós-prandial são ricas fontes destes carboidratos. Os possiveis efeitos dos carboidratos nãodisponiveis no metabolismo da glicose podem estar relacionados com diferentes eventos que ocorrem no trato gastrintestinal superior. Entre os quais, pode ser mencionada a redução da motilidade intestinal e/ou absorção dos carboidratos devido às propriedades viscosas dos componentes da fibra alimentar, ou a redução da velocidade de digestão e/ou absorção dos carboidratos decorrente da encapsulação do substrato pela parede celular. Por outro lado, os AGCC produzidos durante a fermentação colônica dos carboidratos não-disponíveis estão relacionados com efeitos sistêmicos no metabolismo da glicose e dos lipídios (CUMMINGS; MACFARLANE, 1991; ELIA; CUMMINGS, 2007). Assim, tem sido mencionado que a fermentação destes carboidratos leva a uma diminuição dos niveis de glicemia de jejum e aumenta a tolerância à glicose pela supressão dos níveis de ácidos graxos não esterificados e da produção de glicose hepática (THORBURN; MUIR; PROIETTO, 1993).

Os carboidratos não-disponíveis dos alimentos resistem à digestão e/ou absorção e passam para o intestino grosso, onde são parcial ou totalmente fermentados pela microbiota intestinal. O aumento de massa bacteriana, a diminuição do $\mathrm{pH}$ e a produção dos AGCC no intestino, resultantes deste processo, têm efeitos benéficos para o organismo humano e se relacionam com o tratamento e a prevenção de determinadas DCNT (FOLKS; FULLER; 
GIBSON, 1999; WHO; FAO, 2003; GOVINDJI, 2006; GRAY, 2006; NISHIDA; NOCITO; MANN, 2007).

Assim, o impacto dos carboidratos presentes na dieta sobre o metabolismo da glicose depende não somente da quantidade consumida, como se acreditava no passado, mas de uma série de propriedades específicas dos alimentos que podem modificar os efeitos metabólicos. Entre estas propriedades dos carboidratos, estão a velocidade/ extensão de digestão e absorção e tipos de monômeros absorvidos, bem como a extensão, velocidade, local e produtos da fermentação colônica.

Com relação à avaliação dos efeitos da fermentação de carboidratos não-disponiveis sobre o organismo, o grupo tem realizado ensaios in vivo e in vitro com determinadas fontes destes carboidratos. Por exemplo, com a cebola (frutanos), com o Synergy $\left(\mathrm{BENEO}^{\mathrm{TM}}\right.$ ), com a banana verde (amido resistente e fibra alimentar), entre outros.

Os efeitos do consumo de ração adicionada de cebola (Allium cepa, L.) liofilizada ( $10 \%$ de frutanos), como fonte de frutanos, foram avaliados em ratos machos (PASCOAL; LAJOLO; MENEZES, 2005, Anexo 23). Um grupo de animais recebeu dieta controle e o outro recebeu dieta suplementada com cebola liofilizada, por 38 dias. Comparando-se os resultados do grupo experimental (frutanos-10\%) com os do grupo controle, observou-se aumento significante, tanto no peso total das fezes $(p<0,05)$, com bulking index de $0,97 \mathrm{~g}$ $\pm 0,25 \mathrm{~g} / \mathrm{g}$ de frutano ingeridos; como na umidade das fezes $(p<0,05)$ e do conteúdo cecal. Houve diminuição significante no $\mathrm{pH}$ do ceco $(p<0,05)$ no grupo frutanos-10\% em relação ao controle. Ainda, o peso total do ceco, conteúdo cecal e parede do ceco do grupo frutanos-10\% tiveram um aumento significante $(p<0,05)$ em relação ao controle. A ingestão de frutanos aumentou a massa fecal excretada e a umidade das fezes e do conteúdo cecal, o que pode indicar altos níveis de fermentação. Além disso, a ingestão de frutanos causou efeito trófico na parede do ceco, provavelmente devido à fermentação. Detalhes sobre a pesquisa estão descritos na tese de doutorado "Fermentabilidade de frutanos da cebola (Allium cepa L.): estudo in vivo, in vitro e do efeito trófico no intestino grosso" (PASCOAL, 2007).

O processo de fermentação de carboidratos não-disponiveis também pode apresentar benefícios relativos à absorção de minerais. A aquisição de 
massa óssea ocorre até a terceira década de vida e a adequada mineralização óssea constitui a melhor estratégia para prevenção de osteoporose na idade adulta. A única fonte de cálcio é alimentar e sua ingestão pode ser melhorada com um maior consumo de alimentos fontes, fortificação de alimentos e uso de prebióticos. No ensaio clínico realizado pelo grupo, (SOUZA et al., 2007, Anexo 24), foi estudado o efeito do consumo de bebida láctea suplementada com frutanos (inulina e oligofrutose) e cálcio sobre o metabolismo ósseo de meninas de 9 a 12 anos com baixa ingestão de cálcio. Foi elaborada uma formulação de bebida láctea padrão, adicionada de $200 \mathrm{mg}$ de cálcio, e outra teste, adicionada de $200 \mathrm{mg}$ de cálcio e $8,8 \mathrm{~g}$ de frutano (BENEO ${ }^{\mathrm{TM}}$ Synergy 1 ). Ambas foram avaliadas quanto aos aspectos químicos, microbiológicos e sensoriais. Para o estudo, foram selecionadas 60 participantes entre as alunas matriculadas nas escolas públicas de Umuarama, PR. As voluntárias, prépuberes com consumo de cálcio $<75 \%$ da ingestão adequada (aproximadamente $500 \mathrm{mg} / \mathrm{dia}$ ), foram submetidas à triagem por meio de avaliação antropométrica, de estilo de vida, de consumo alimentar e estádio puberal de Tanner, e foram divididas de forma aleatória em três grupos. Os grupos 1 e 2 participaram de experimento duplo cego tipo crossover e receberam suplementação de uma porção diária de bebida láctea com cálcio ou de bebida láctea com cálcio e frutano, por onze semanas cada e com intervalo de 3 semanas (washout). O grupo 3 não recebeu nenhuma suplementação e foi considerado como grupo controle. As participantes foram submetidas a oito avaliações bioquímicas, que incluíram análises séricas de cálcio, paratormônio intacto (PTHi), fosfatase alcalina fração específica óssea $(F A O)$ e osteocalcina $(O C)$. O grupo 1, que iniciou a suplementação com cálcio e no segundo período foi suplementado com cálcio e frutano, apresentou aumento significante de FAO e cálcio, além de redução do PTHi, no segundo período experimental em relação ao primeiro período. O efeito benéfico dos frutanos foi evidenciado somente após a suplementação preliminar com $200 \mathrm{mg}$ de cálcio por onze semanas, o que pode indicar uma possível dependência da concentração de cálcio alimentar em populações com baixa ingestão desse nutriente. Detalhes sobre a pesquisa estão descritos na tese de doutorado "Efeito da suplementação de frutanos e cálcio no metabolismo ósseo de meninas com baixa ingestão de cálcio" (SOUZA, 2007). 
Outra fonte de carboidratos não-disponiveis é a banana, que tem sido estudada pelo grupo sob diferentes aspectos (NASCIMENTO et al., 2006; MAINARDI et al., 2006; CORDENUNSI; SHIGA; LAJOLO, 2008). Visando a seleção de cultivares para serem utilizadas na elaboração de produtos, o grupo avaliou a composição química e as características físico-químicas do amido da farinha preparada da partir de oito cultivares de banana verde (CORDENUNSI et al., 2000).

O projeto $\mathrm{CNPq}$ "Estudo da fermentação in vitro e in vivo da fração indigerivel de carboidratos" (Processo 301494/2004-5), finalizado em 2007 (MENEZES, 2007c), resultou na produção e orientação pela pesquisadora de uma tese de doutorado "Produtos derivados de banana verde e sua influência na tolerância à glicose e na fermentação colônica" (CARDENETTE, 2006) e uma dissertação de mestrado "Efeito trófico dos carboidratos não-disponíveis de banana/plátano verde sobre o intestino grosso de ratos adultos" (DAN, 2007), do curso de Pós-graduação em Ciência dos Alimentos FCF/ USP. Os produtos de banana verde estudados (amido isolado de banana verde - ABV e farinha de banana verde cozida com casca - MBV) apresentaram alta concentração de carboidratos não-disponíveis e com alta fermentabilidade. Essa alta fermentabilidade foi evidenciada pelo aumento da produção de ácidos graxos de cadeia curta (AGCC) e diminuição de pH na fermentação colônica tanto in vitro como in vivo (DAN et al., 2006). Parâmetros macroscópicos e a análise histológica de tecido do ceco mostraram que esses produtos exerceram efeito trófico no intestino grosso de ratos adultos. Os produtos proporcionaram menor secreção de insulina pelas ilhotas pancreáticas dos animais, bem como redução nos niveis de insulina plasmática para manter glicemias semelhantes, sinalizando uma possivel melhora da tolerância à glicose. Os resultados indicam que os produtos de banana verde estudados têm grande potencial para serem utilizados na elaboração de alimentos destinados à prevenção de determinadas doenças crônicas nãotransmissíveis, necessitando que seus efeitos nutricionais sejam avaliados em ensaios clínicos com humanos. Uma primeira publicação destes resultados foi enviada para o Food Research International, em março de 2008 (CARDENETTE, et al., enviado). Neste trabalho é feita a comparação entre métodos in vivo e in vitro para avaliação da fermentação colônica de dietas, 
tendo os produtos de banana verde como fontes de carboidratos nãodisponiveis. Outros trabalhos que estão sendo redigidos, envolvem a influência da fermentação de carboidratos não-disponiveis da banana verde sobre a tolerância à glicose e sobre o efeito trófico no intestino grosso de ratos.

Esse projeto possibilitou a padronização e a validação de inúmeras metodologias tanto in vivo como in vitro, as quais hoje são utilizadas por vários alunos de pós-graduação do Laboratório de Química, Bioquímica e Biologia Molecular, da FCF/USP. Os resultados com animais, humanos e químicos obtidos, com o amido isolado de banana verde (ABV) e com a farinha de banana verde cozida com casca (MBV), possibilitaram o conhecimento detalhado sobre os efeitos da fermentação colônica dos carboidratos nãodisponíveis da banana verde, permitindo o planejamento de um novo projeto.

Este novo projeto "Potencial da farinha de banana verde como ingrediente funcional: I. Efeito sobre a saciedade e resposta glicêmica em humanos e perfil de fermentação in vitro; II. Efeito da fermentação dos carboidratos não-disponíveis sobre a tolerância à glicose e efeito trófico no intestino grosso em ensaios de média duração em ratos" já foi aprovado pelo CNPq, 2008-2010 (processo: 302825/2007-0). Basicamente, este projeto tem como meta oferecer uma alternativa alimentar para solucionar problemas relativos ao desequilíbrio entre o aporte energético da dieta ingerida e o gasto de energia, através do controle do apetite e da resposta glicêmica, por exemplo; bem como avaliar de que forma a fermentação colônica dos carboidratos não-disponíveis participam deste contexto.

O desenvolvimento do processo tecnológico para produção da farinha de banana verde foi realizado em 2007 e os ensaios clínicos com humanos, validados em outros projetos do grupo, já foram iniciados em 2008.

Em parceria com pesquisadores do Departamento de Engenharia Química, da Escola Politécnica da Universidade de São Paulo, foram realizados estudos para desenvolver tecnologia para produção de farinha de banana verde. O processo de obtenção da farinha de banana verde (Musa acuminata, subgrupo cavendishii, var. Nanicão) foi estudado desde a matériaprima até o produto final, com a preocupação da manutenção do conteúdo máximo de amido resistente do produto e a obtenção da farinha de banana verde com boas características tecnológicas, a fim de viabilizar a sua aplicação 
na substituição de farinhas convencionais em formulações alimentícias. A farinha de banana verde produzida foi analisada quanto às suas características tecnológicas (análises térmicas, comportamento viscoamilográfico, análises reológicas) e comparada à farinha de trigo, com o objetivo de prever seu comportamento diante das alterações ocorridas durante a elaboração e processamento de formulações alimentícias.

Durante a primeira etapa foi estudada a matéria-prima no decorrer dos dias de armazenagem, quanto ao conteúdo de amido resistente $e$ caracterização físico-química. Para isso, realizou-se o acompanhamento da maturação dos frutos em dois períodos de safra distintos (em 2006 e 2007), em 120 frutos analisados em triplicatas, e verificou-se que as bananas, quando não expostas às câmaras de maturação, permanecem no estágio I de maturação por até 16 dias após a colheita. Essa constatação contribui com a logística da matéria-prima, com a redução das perdas decorrentes de um amadurecimento acelerado e garantem uma matéria-prima com conteúdo de amido resistente mantido (GOMES et al., 2007).

Para a manutenção da coloração do produto durante o processamento, foi estudado o efeito de pré-tratamentos para evitar o escurecimento enzimático, não-enzimático e conversão das antocianinas. Para isso, foram realizados diversos testes de pré-tratamentos térmicos e químicos do produto até convergirem no pré-tratamento químico em solução de ácido cítrico $0,1 \%$, para imersão das bananas em duas etapas do processo (após o descascamento e após o fatiamento da polpa). Dessa forma, obtém-se uma farinha com coloração mais próxima à da farinha de trigo (TRIBESS et al., 2006, Anexo 25).

Durante a produção da farinha de banana verde é realizada, obrigatoriamente, a etapa de secagem durante a qual o produto não pode sofrer alterações decorrentes da ação da temperatura, como a gelatinização, que tem como conseqüência a redução do conteúdo de amido resistente do produto. Para evitar a gelatinização do amido presente na banana verde, foi realizado estudo da secagem em diferentes condições de temperatura e velocidade do ar, buscando a produção da farinha de banana verde com conteúdo máximo de amido resistente. Este objetivo foi alcançado por meio da 
secagem do produto na temperatura de $55^{\circ} \mathrm{C}$ e velocidade do ar de $1,4 \mathrm{~m} / \mathrm{s}$ (TRIBESS et al., enviado).

O processo tecnológico para produção da farinha foi concluído e a farinha resultante está pronta para ser utilizada como ingrediente em outros produtos, tais como bolos, pães, barras de cereais, biscoitos e sopas desidratadas. O depósito de pedido de patente de invenção "Processo de produção de farinha proveniente da banana verde", junto ao Instituto Nacional de Propriedade Industrial - I.N.P.I./SP, foi realizado em 12 de julho de 2007, protocolo $\mathrm{n}^{\circ}$ 018070044163, tendo como autores: Elizabete Wenzel de Menezes; Franco M. Lajolo; Carmen Tadini; Tatiana Tribess (MENEZES et al., 2007, Anexo 26).

O grupo já iniciou os estudos para a avaliação da potencialidade desta farinha de banana verde como ingrediente funcional, envolvendo uma dissertação de mestrado e uma tese de doutorado. Nesses estudos, a farinha de banana verde (FBV) será adicionada a refeições prontas e serão realizados estudos in vivo (ratos e voluntários saudáveis) e in vitro. Os principais parâmetros a serem avaliados são: perfil de carboidratos da farinha de banana verde; perfil fermentativo da fração não-disponível; efeito sobre a saciedade, hormônios gastrintestinais e parâmetros relacionados à tolerância à glicose efeito trófico, decorrente da fermentação de carboidratos não-disponíveis no intestino grosso de ratos adultos; correlação entre os resultados obtidos in vivo e in vitro.

Testes iniciais da aplicação da farinha de banana verde (FBV) na formulação de barras de cereais diet foram realizados, e os resultados obtidos sinalizam para uma boa alternativa para aplicação da farinha de banana verde (VIDAL et al., 2007, Anexo 27). O produto final apresentou características sensoriais próximas às formulações originais e sem perdas no conteúdo de amido resistente da farinha, uma vez que a barra de cereais não passa por etapa de aquecimento durante seu processamento. O estudo nutricional das barras de cereais, elaboradas com FBV, já foi iniciado e envolve o desenvolvimento de uma dissertação de mestrado, a qual e tem como objetivo avaliar a resposta glicêmica pós-prandial produzida após sua ingestão e o perfil de fermentação in vitro do produto. 


\subsection{Banco de dados e tabelas de composição de alimentos}

Pesquisadores do Departamento de Alimentos e Nutrição Experimental da FCF já estavam envolvidos na geração de dados de composição de alimentos muito antes do início de meu envolvimento nesta linha de pesquisa (LAJOLO, 1987; LAJOLO; VANNUCCHI, 1987; LAJOLO, 1995). Após minha participação no Taller CTPD sobre producción y manejo de datos de composición química de alimentos en nutrición, organizado pelo INFOODS, LATINFOODS e FAO, no Chile, em 1995, iniciei as atividades nessa área, tendo como meta principal a produção de uma tabela nacional de composição de alimentos de acordo com normas internacionais e critérios estabelecidos pelo LATINFOODS e INFOODS para a região.

Juntamente com o Prof. Lajolo coordenei inúmeras atividades e publicações, sempre visando melhorar a qualidade, a produção e a disseminação dos dados nacionais de composição de alimentos. Alguns dos temas abordados estão descritos a seguir: 1) Tabelas de composição de alimentos: Análise retrospectiva e contextualização da questão, trabalho que contém um diagnóstico da situação dos dados de composição de alimentos no Brasil e as ações a serem desenvolvidas a curto, médio e longo prazo (LAJOLO; MENEZES, 1997); 2) Uniformização internacional de dados brasileiros de composição de alimentos (MENEZES; CARUSO; LAJOLO; 1997); 3) Disponibilização na internet da primeira versão da Tabela Brasileira de Composição de Alimentos (TBCA-USP) (http://www.fcf.usp.br/tabela) (USP, 1998, Anexo 3); 4) Modelos esquemáticos para avaliação da qualidade analítica dos dados nacionais de fibra alimentar (CARUSO; LAJOLO; MENEZES, 1999, Anexo 4); 5) Aplicação de critérios para avaliação da qualidade de dados de fibra alimentar em alimentos brasileiros (MENEZES; CARUSO; LAJOLO, 2000, Anexo 5); 6) Tabela Brasileira de Composição de Alimentos - USP (MENEZES; LAJOLO, 2001); 7) Quantificação e caracterização de amido dos alimentos (ROSIN; LAJOLO; MENEZES, 2002, Anexo 12); 8) Tabela Brasileira de Composição de Alimentos (TBCA-USP): Inclusão de informações complementares e dados referentes à fração carboidrato (DAN; LAJOLO; MENEZES, 2003); 9) Formulário para compilação de dados de composição de alimentos: TBCA-USP (RATTO et al., 2003); 10) Tabela Brasileira de Composição de Alimentos: TBCA-USP versão 2003 
(GIUNTINI et al., 2003); 11) Tabela Brasileira de Composição de Alimentos: TBCA-USP 4.0 (GIUNTINI et al., 2004); 12) II Conferência Eletrônica FAO/LATINFOODS "Avaliação da qualidade dos dados para bases de dados e tabelas de composição química de alimentos", a qual foi realizada pela USP, LATINFOODS e FAO, e teve por objetivo aprofundar a discussão sobre os aspectos associados à avaliação da qualidade de dados para bases de dados e tabelas de composição química de alimentos nacionais, subregionais e regional. Foram disponibilizados na internet os seguintes documentos: textos para discussão; nota informativa e informe final (MENEZES; MORÓN; GIUNTINI, 2004); 13) Indústria e Comércio Alimentar. Material de divulgação, em espanhol, que visa a obtenção da cooperação das indústrias de alimentos no fornecimento de dados analíticos de alimentos para implementar a Tabela de Composição de Alimentos da América Latina (LATINFOODS) e tabelas de cada país da América Latina, como a TBCA-USP (MENEZES, 2004); 14) Composição de alimentos: um pouco de história (GIUNTINI; LAJOLO; MENEZES, 2006a); 15) LATINFOODS: Atividades de composição de alimentos na América Latina (2004-2006) (MENEZES et al., 2007); 16) $7^{\text {a }}$ Conferência Internacional de Dados de Composição de Alimentos - Composição de Alimentos e Biodiversidade (MENEZES; LAJOLO, 2007). Em função do significativo trabalho que o BRASILFOODS vem desenvolvendo na área de composição de alimentos e dos êxitos obtidos pelo LATINFOODS, quando fui presidente desta rede, o BRASILFOODS e a USP foram escolhidos, pela FAO e INFOODS, para organizar a " 7 th International Food Data Conference Food Composition and Biodiversity e a "Expert Consultation on Nutrition Indicators for Biodiversity", em São Paulo, de 21 a 24 de outubro de 2007. A incumbência de organizar estes eventos, os quais foram de excelente qualidade e contaram com participação de 110 pesquisadores de 35 paises, exemplificam bem a integração do BRASILFOODS no contexto latino-americano e internacional.

Cabe ressaltar que a TBCA-USP (USP, 1998, Anexo 3) foi a primeira base de dados disponibilizada pela internet na América Latina, e que o BRASILFOODS periodicamente atualiza com dados brasileiros a base de dados da América Latina (LATINFOODS) (FAO; LATINFOODS, 2000).

Aos temas desenvolvidos pelo BRASILFOODS, acima descritos, podem ser acrescidas cinco publicações. Estes trabalhos mostram que a criação de 
uma tabela de composição de alimentos em um país não finaliza o assunto e, sim, que foi criada uma estrutura onde novos dados deverão ser continuamente inseridos e modificações deverão ser periodicamente realizadas, em função das necessidades dos usuários, das condições das informações existentes (qualidade) e da geração de novos dados.

No anexo 28 (MENEZES et al., 2002, Anexo 28), estão descritos aspectos relacionados com a evolução da base de dados da TBCA-USP, até 2000 , quanto ao seu conteúdo, avaliação da qualidade dos dados, estrutura e dificuldades, bem como as modificações necessárias para a adequada disseminação na internet. O conhecimento dos aspectos positivos e negativos da base de dados, além da identificação das razões que os determinaram, pode contribuir para melhorar a base como um todo. Partindo destas observações, inúmeras atividades passaram a ser priorizadas a fim de serem incluídas nas próximas versões, como por exemplo: otimização da busca de dados por alimentos; compilação de novos dados; análise de novos alimentos e nutrientes, e também a procura por novas parcerias e apoio financeiro do governo.

A identificação de aspectos básicos necessários para possibilitar comparação de dados analíticos é discutida na publicação do anexo 29 (MENEZES; GIUNTINI; LAJOLO, 2003, Anexo 29). Os dados de composição de alimentos não podem ser considerados absolutos, pois se referem a material biológico, apresentam variações em função de inúmeros fatores como safra, variedade, solo, clima, formulação, preparação, entre outros; além disso, os valores apresentados em uma tabela representam uma estimativa média, referente a um determinado número de amostras ou alimentos compilados. É importante assegurar que as informações sobre composição de alimentos disponibilizadas aos profissionais sejam de qualidade. Estas informações devem ser obtidas mediante a adoção de diversos critérios, que envolvem basicamente a descrição detalhada do alimento e de todo o processo analítico, desde a amostragem até o controle da qualidade analítica, bem como do procedimento de compilação utilizado.

Conforme descrito no anexo 29 (MENEZES; GIUNTINI; LAJOLO, 2003, Anexo 29), a inclusão de dados em um banco envolve vários aspectos, tais como a documentação detalhada sobre a identificação do alimento, plano de 
amostragem, métodos analíticos, qualidade dos procedimentos de análise, entre outros. Para otimizar o trabalho de compilação e promover uma uniformização das informações, foi desenvolvido um formulário que contém planilhas independentes para compilação de dados dos vários nutrientes e de identificação do alimento, e inclui também um manual para orientar o preenchimento do formulário (MENEZES et al., 2005, Anexo 30). O formulário padronizado é uma ferramenta importante para garantir a qualidade dos dados, com o objetivo de oferecer informações cada vez mais completas e direcionadas para as necessidades dos usuários. Este formulário está disponivel online na TBCA-USP (http://www.fcf.usp.br/tabela) e foi traduzido para o espanhol para ser utilizado nas redes de composição de alimentos da América Latina (LATINFOODS).

Após a versão da TBCA-USP, descrita no Anexo 28 (MENEZES et al., 2002), foram desenvolvidas e disponibilizadas na internet as versões TBCAUSP 3.0, 4.0 e 4.1, que apresentaram inúmeras modificações estruturais e de layout (GIUNTINI; LAJOLO; MENEZES, 2006b, Anexo 31). A versão 3.0 da TBCA-USP apresentava uma tabela blocada com os alimentos separados por grupos, devido ao grande número de informações. Como esse número continuou aumentando, as versões 4.0/4.1 passaram a apresentar os dados dos alimentos de maneira individualizada, acessada por busca e pelo nome do alimento (em português, inglês ou nome científico). Os dados são apresentados por 100g/alimento e medidas caseiras usuais e cita, para cada alimento, a porção individual recomendada pela Agência Nacional de Vigilância Sanitária do Ministério da Saúde (ANVISA). No trabalho estão descritas também as atividades futuras do BRASILFOODS, entre as quais está a criação de bancos específicos de nutrientes (carboidratos e resposta glicêmica, compostos bioativos) ou alimentos com propriedade funcional.

Para finalizar esta parte do trabalho, está apresentado no Anexo 32 um capítulo de livro que inclui detalhada revisão sobre tabelas e bancos de dados de composição de alimentos (MENEZES; GIUNTINI, aceito, Anexo 32). Este capítulo foi aceito para ser publicado na $2^{\mathrm{a}}$ edição do livro Ciências Nutricionais dos professores Dutra-de-Oliveira e Marchini. Entre os temas discutidos estão: evolução do estudo de composição de alimentos; participação da FAO, UNU e INFOODS na produção de bancos de dados; elaboração de bancos de dados e 
tabelas; variabilidades de valores de composição de alimentos; principais tabelas utilizadas no Brasil; Tabela Brasileira de Composição de Alimentos (TBCA-USP).

Os trabalhos apresentados neste tópico mostram a evolução da TBCAUSP antes e depois de sua criação em 1998, e refletem também todo o esforço da coordenação da base de dados e do BRASILFOODS para melhorar a qualidade dos dados nacionais de composição de alimentos e facilitar a troca de informação entre os analistas, compiladores e usuários, tanto nacionais como internacionais. Ao mesmo tempo, mostram a importância que as pesquisas em composição de alimentos atingiram no Brasil, sendo que as atividades desenvolvidas pelo BRASILFOODS servem de referência, em composição de alimentos, para diversos países da América Latina. 


\section{COMENTÁRIOS FINAIS E PERSPECTIVAS FUTURAS}

Para o grupo poder avaliar a real ingestão de fibra alimentar pela população brasileira, ficou bastante claro que uma série de atividades paralelas tiveram que ser desenvolvidas, podendo ser mencionada a ampliação dos estudos em composição de alimentos. A ingestão de fibra alimentar pela população brasileira caiu de forma significativa da década de 70 a 90 , sendo da ordem de $15,4 \mathrm{~g} /$ dia na década atual. O mesmo ocorreu com o amido resistente e sua ingestão atual é de $3,7 \mathrm{~g} / \mathrm{dia}$. Para chegar a esses números, produtos adicionais foram desenvolvidos, como os banco de dados de fibra alimentar e amido resistente para alimentos nacionais e uma base de dados destes componentes de países ibero-americanos. Paralelamente, foi desenvolvida e disponibilizada na internet uma base de dados nacional de composição de alimentos (Tabela Brasileira de Composição de Alimentos - TBCA/USP), bem como inúmeras atividades e publicações foram desenvolvidas para melhorar a qualidade, a produção e a disseminação de dados nacionais de composição de alimentos. Esta base de dados, que contém informação de composição química de 1800 alimentos, é considerada referência nacional em composição de alimentos e vem sendo adotada como modelo por outros países da América Latina.

Entre as atividades futuras, pretende-se: continuar atualizando e implementando a TBCA-USP com novos alimentos e novos nutrientes; concluir . e disponibilizar a base de dados de carboidratos e de resposta glicêmica; atualizar o sistema de avaliação da qualidade de dados de fibra alimentar $e$ criar sistema para os demais componentes, utilizando os modelos propostos pelo USDA (HOLDEN; BHAGWAT; PATTERSON, 2002; HOLDEN et al., 2005; HAYTOWITZ; PEHRSSON; HOLDEN, 2007); continuar fornecendo dados sobre as estimativas nacionais de ingestão de fibra alimentar e de amido resistente.

Com relação ao aproveitamento de carboidratos de alimentos, os estudos apresentados resultaram na implantação e validação de inúmeras técnicas, tanto in vivo como in vitro, no nosso laboratório de pesquisa; permitiram a sedimentação de conhecimento sobre possíveis efeitos fisiológicos dos carboidratos não-disponiveis decorrentes do seu limitado 
aproveitamento no intestino delgado e de sua fermentabilidade no intestino grosso; e, finalmente, possibilitaram a definição e elaboração de produto com potencial de ingrediente funcional (farinha de banana verde).

Cabe, agora, a realização de estudos com este produto e com seus derivados. Alguns ensaios planejados podem ser mencionados: avaliação da fermentação in vitro e caracterização quimica; avaliação do produto sobre a resposta glicêmica, saciedade, liberação de hormônios gastrintestinais e perfil de funcionamento intestinal (ensaios clínicos com voluntários saudáveis); avaliação dos carboidratos não-disponíveis da banana verde sobre a morfometria e proliferação celular de tecido do intestino grosso e sobre tolerância à glicose, utilizando modelo de secreção de insulina pelas ilhotas pancreáticas e teste de tolerância à glicose (ensaios em ratos). 


\section{REFERÊNCIAS BIBLIOGRÁFICAS}

AUGUSTIN, LS; FRANCESCHI, S; JENKINS, DJ; KENDALL, CW; La VECCHIA, C. Glycemic index in chronic disease: a review. Eur. J. Clin. Nutr., v.56 (11), p.1049-71, 2002.

BENGOA, JM; TORUM, B; BEHAR, M; SCRIMSHAW, N, eds. Guias de alimentación. Bases para su desarrollo en América. Fundación Cavendes, Caracas, 1988. 54p. [Taller celebrado em Caracas, de 22 a 28 de novembro de 1987].

BIGWOOD, DW; HELLER, SR; WOLF, WR; SCHUBERT, A; HOLDEN, JM. SELEX: an expert system for evaluating published data on selenium in foods. Anal. Chim. Acta, v.200, p.411-419, 1987.

BJÖRCK, I. Starch: nutritional aspects. In: ELIASSON, AC, ed. Carbohydrates in food. Marcel Dekker Inc., 1996. p.505-553.

BRAND-MILLER, JC. Glycemic load and chronic disease. Nutr. Rev., v.61 (5), p.S49-S55, 2003.

CARDENETTE, GHL. Produtos derivados de banana verde (Musa ssp) e sua influência na tolerância à glicose e na fermentação colônica, São Paulo, 2006, 187p. [Tese de Doutorado - Faculdade de Ciências Farmacêuticas da Universidade de São Paulo].

CARDENETTE, GL; DAN, MCT; GOÑI, I; BELLO-PÉREZ, LA; LAJOLO, FM; MENEZES, EW: Colonic fermentation of rat diets containing products of unripe banana: in vivo and in vitro assays. Food Res. Int. (enviado para publicação em março de 2008).

CARREIRA, MC; LAJOLO, FM; MENEZES, EW. Glycemic index: Effect of food storage under low temperature. Braz. Arch. Biol. Technol., v.47 (4), p.569-574, 2004.

CARUSO, L; LAJOLO, FM; MENEZES, EW. Modelos esquemáticos para avaliação da qualidade analítica dos dados nacionais de fibra alimentar. Ci. Tecnol. Aliment., v.19 (3), p.406-412, 1999.

CARUSO, L; MENEZES, EW. Índice glicêmico dos alimentos. Nutrire, v.19/20, p.49-64, 2000.

CORDENUNSI, BR; MENEZES, EW; GENOVESE, MI; COLLI, C; SOUZA, AG; LAJOLO, FM. Chemical composition and glycemic index of Brazilian pine (Araucaria angustifolia) seeds. J. Agr. Food Chem., v.52 (11), p.34123416, 2004. A21

CORDENUNSI, BR; MENEZES, EW; MOTA, RV; LAJOLO, FM. Composição em carboidratos em banana verde e madura de diferentes cultivares. Anais da Conferência del Proyecto de Investigación Precompetitiva CYTED XI.8. Quito, 2000. p. 15-22. [Conferência realizada em Baños, Ecuador, de 02 a 04 de setembro de 1998].

CORDENUNSI, BR; SHIGA, TM; LAJOLO, FM. Non-starch polysaccharide composition of two cultivars of banana (Musa acuminata L.: cvs Mysore and Nanicão). Carbohyd. Polym., v.71, p.26-31, 2008.

CUMMINGS, JH; MACFARLANE, GT. The control of bacterial fermentation in the human colon. J. Appl. Bacteriol., v.70 (6), p.443-59, 1991.

CUMMINGS, JH; STEPHEN, AM. Carbohydrate terminology and classification. Eur. J. Clin. Nutr., v.61 (Suppl 1), p.S5-S18, 2007.

DAN, MCT. Efeito trófico dos carboidratos não-disponíveis de banana/plátano verde sobre o intestino grosso de ratos adultos, São Paulo, 2007, 85p. 
[Dissertação de Mestrado - Faculdade de Ciências Farmacêuticas da Universidade de São Paulo].

DAN, MCT; CARDENETTE, G; GOÑI, I; MENEZES, EW; LAJOLO, FM. Fermentabilidade de produtos de banana verde. Rev. Bras. Cienc. Farm., v.42 (Supl1), p.31, 2006.

DAN, MCT; LAJOLO, FM; MENEZES, EW. Tabela Brasileira de Composição de Alimentos (TBCA-USP): Inclusão de informações complementares e dados referentes à fração carboidrato. Rev. Bras. Cienc. Farm., v.39 (3), p.177-179, 2003.

DANONE VITAPOLE; FAO, eds. Glycaemic index and health, the quality of the evidence. Nutrition and Health Collection. John Libbey Eurotext, França, 2001. 48p.

ELIA, M; CUMMINGS, JH. Physiological aspects of energy metabolism and gastrointestinal effects of carbohydrates. Eur. J. Clin. Nutr., v.61 (Suppl 1), p.S40-S74, 2007.

ENGLYST, KN; LIU, S; ENGLYST, HN. Nutritional characterization and measuremment of dietary carbohydrate. Eur. J. Clin. Nutr., 61 (Suppl 1), S19-S39, 2007.

ENGLYST, KN; VINOY, S; ENGLYST, HN; LANG, V. Glycaemic index of cereal products explained by their content of rapidly and slowly available glucose. Br. J. Nutr., v.89 (3), p.329-39, 2003.

FOLKS, LJ; FULLER, R; GIBSON, GR. Prebiotcs, probiotics and human gut microbiology. Int. Dairy J., v.9, p.53-61, 1999.

FOOD AND AGRICULTURE ORGANIZATION; RED LATINOAMERICANA DE DATOS DE COMPOSICIÓN DE ALIMENTOS (FAO; LATINFOODS). Tabla de Composición de Alimentos de América Latina. LATINFOODS, Santiago, Chile, 2000. Disponível em: http://www.rlc.fao.org/bases/ alimento. Acesso em fevereiro de 2006.

FOOD AND AGRICULTURE ORGANIZATION; WORLD HEALTH ORGANIZATION (FAO; WHO) Carbohydrates in human nutrition. Report of a joint FAOMHO expert consulation, April 14-18, 1997. Food and Nutrition Paper, v.66, FAO, Rome, 1998. 140p.

FOSTER-POWELL, K; BRAND-MILLER, JC. International tables of glycemic index. Am. J. Clin. Nutr., v.62, p.S871-S935, 1995.

FOSTER-POWELL, K; HOLT, SHA; BRAND-MILLER, JC. International table of glycemic index and glycemic load values: 2002. Am. J. Clin. Nutr., v.76, p.5-56, 2002.

FUNDAÇÃO INSTITUTO BRASILEIRO DE GEOGRAFIA E ESTATÍSTICA (IBGE). Pesquisa de Orçamento Familiar (POF) 2002/2003. Análise da disponibilidade domiciliar de alimentos e do estado nutricional no Brasil. Ministério do Planejamento, Orçamento e Gestão. Rio de Janeiro. 2004. Disponivel em: http://www.ibge.gov.br/home/estatistica/populacao/ condicaodevida/pof/2002analise/default.shtm. Acesso em: janeiro de 2005.

GIBSON, GR; PROBERT, HM; LOO, JV; RASTALL, RA; ROBERFROID, MB. Dietary modulation of the human colonic microbiota: updating the concept of prebiotics. Nutr. Res. Rev., v.17, p.259-75, 2004.

GIBSON, GR; ROBERFROID, M. Dietary modulation of the human colonic microbiota: introducing the concept of prebiotics. J. Nutr., v.125, p.14011412, 1995. 
GIUNTINI, EB; LAJOLO, FM; MENEZES, EW. Composição de alimentos: um pouco de história. Arch. Latinoam. Nutr., v.56 (3), p.295-303, 2006a.

GIUNTINI, EB; LAJOLO, FM; MENEZES, EW. Tabela Brasileira de Composição de Alimentos TBCA-USP (Versões 3 e 4) no contexto internacional. Arch. Latinoam. Nutr., v.56 (4), p.366-374, $2006 \mathrm{~b}$.

GIUNTINI, EB; MENEZES, EW; LAJOLO, FM. Potencial de fibra alimentar em países ibero-americanos: Alimentos, produtos e resíduos. Arch. Latinoam. Nutr., v.53 (1), p.14-20, 2003.

GIUNTINI, EB; RATTO, AT; LAJOLO, FM; MENEZES, EW. Tabela Brasileira de Composição de Alimentos: TBCA-USP versão 2003. Rev. Bras. Cienc. Farm., v.39 (3), p.137-140, 2003.

GIUNTINI, EB; RATTO, AT; LAJOLO, FM; MENEZES, EW. Tabela Brasileira de Composição de Alimentos: TBCA-USP 4.0. Anais do XIX CBCTA. Recife, 2004. [Congresso realizado em Fortaleza, de 07 a 10 de setembro de 2004].

GOMES, AZ; TRIBESS, TB; SIERRA, LBV; TADINI, CC. Características físicoquímicas e de firmeza da banana verde (Musa sp., variedade Nanica) não-maturada durante o armazenamento. Anais do COBEQ-IC, 2007.

GOÑI, IC; GARCIA-ALONSO, A; SAURA-CALIXTO, F. A starch hydrolysis procedure to estimate glycemic index. Nutr. Res., v.17 (3), p.427-437, 1997.

GOÑI, IC; MARTÍN-CARRÓN, N. Fermentación colónica de fibra dietética y almidón resistente. In: LAJOLO, FM; SAURA-CALIXTO, F; WITTIG DE PENNA, E, MENEZES, EW, eds. Fibra dietética en Iberoamérica: Tecnología y salud. Obtención, caracterización, efecto fisiológico y aplicación en alimentos. CYTED, CNPq, Varela, São Paulo, 2001. p.311-338.

GOVINDJI, A. The role of carbohydrates in a healthy diet. Nurs. Stand., v.21 (3), p.56-64, 2006.

GRAY, J. Dietary fibre - Definition, analysis, physiology and health. ILSI Europe Consise Monograph Series. 2006. 36p.

GREENFIELD, H; SOUTHGATE, DAT. Food Composition data: production, management and use. 2ed. Food and Agriculture Organization of United Nations (FAO), Rome, 2003. 288p.

HAYTOWITZ, DB; PEHRSSON, PR; HOLDEN, JM. The national food and nutrient analysis program: A decade of progress. J. Food Comp. Anal., v.21 (Supp. 1), p.S94-S102, 2007.

HOLDEN, JM, SCHUBERT, A, WOLF, WR; BEECHER, GR. A system for evaluating the quality of published nutrient data: selenium, a test case. In: RAND, WM; WINDHAM, CT; WYSE, BM; YOUNG, VR, eds. Food composition data: a user's perspective. United Nations University, Tokyo, 1987. p.177-193.

HOLDEN, JM; BHAGWAT, SA; HAYTOWITZ, D; GEBHARDT, S; DWYER, J; PETERSON, J; BEECHER, GR; ELDRIDGE, AL. Development of a database of critically evaluated flavonoid data: Application of USDA's data quality evaluation system. J. Food Comp. Anal., v.18, p.829-844, 2005.

HOLDEN, JM; BHAGWAT, SA; PATTERSON, KY. Development of a multinutrient data quality evaluation system. J. Food Comp. Anal., v.15 (4), p.339-348, 2002. 
JENKINS, DJA; WOLEVER, TMS; TAYLOR, RH; BARKER, H; FIELDER, $\mathrm{H}$; BALDWIN, JM; BOWLING, AC; NEWMAN, HC; JENKINS, AL; GOFF, D $V$. Glycemic index of foods: a physiological basis for carbohydrates exchange. Am. J. Clin. Nutr., v.34, p.362-366, 1981.

KEY, TJ; SPENCER, EA. Carbohydrates and cancer: an overview of the epidemiological evidence. Eur. J. Clin. Nutr., v.61 (Suppl 1), p.S112S121, 2007.

LAJOLO, FM. Efeito do processamento sobre o valor nutricional dos alimentos. Situação na América Latina e Caribe e importância para a elaboração de tabelas de composição. Arch. Latinoam. Nutr., v.37 (4), p.666-672, 1987.

LAJOLO, FM. Grupo de trabalho: Composição de alimentos. Bol. SBCTA, v.29 (1), p.57-69, 1995.

LAJOLO, FM. Inibidor de amilase do Phaseolus vulgaris: Estudo bromatológico. São Paulo, 1977.133p. [Tese de Livre-Docência Faculdade de Ciências Farmacêuticas da Universidade de São Paulo].

LAJOLO, FM; FILISETTI-COZZI, TMCC; MENEZES, EW. Carboidratos e Fibras. In: CARRAZZA, F; MARCONDES E, eds. Nutrição clínica em pediatria. Sarvier, São Paulo, 1991. p.61-84.

LAJOLO, FM; FINARDI-FILHO, F; MENEZES, EW. Amylase inhibitors in Phaseolus vulgaris beans. Food Technol., v.45 (9), p.119-121, 1991.

LAJOLO, FM; MANCINI-FILHO, J; MENEZES, EW. Effect of a bean (Phaseolus vulgaris, L.) alfa-amylase inhibitor on starch utilization. Nutr. Rep. Int., v.30 (1), p.45-55,1984.

LAJOLO, FM; MENEZES, EW, eds. Carbohidratos en alimentos regionales iberoamericanos. Proyecto CYTED XI.18 "Composición, estructura, propiedades biológicas de carbohidratos y su utilización en alimentos", CNPq, EDUSP, São Paulo, 2006. 648 p.

LAJOLO, FM; MENEZES, EW. Dietary fiber and resistant starch intake in Brazil: Recommendations and actual consumption patterns. In: $\mathrm{CHO}, \mathrm{SS}$; DREHER, M L, eds. Handbook of dietary fiber. Marcel Dekker NY, NY, 2001. p.845-858.

LAJOLO, FM; MENEZES, EW. Uma análise retrospectiva e contextualização da questão. Grupo de Trabalho de Composição de Alimentos. Bol. SBCTA, v.31 (2), p.90-92, 1997.

LAJOLO, FM; MENEZES, EW; FILISETTI-COZZI, TMCC. Considerações sobre carboidratos e fibra. Arch. Latinoamer. Nutr., v.38 (3), p.519-542, 1988 a.

LAJOLO, FM; MENEZES, EW; FILISETTI-COZZI, TMCC. Considerações sobre carboidratos e fibra. In: BENGOA, JM; TORUM, B; BEHAR, M; SCRIMSHAW, $\mathrm{N}$, eds. Metas nutricionales y guias de alimentación para America Latina. Bases para su desarrollo. Fundación Cavendes, Caracas, 1988b. p. 147-170.

LAJOLO, FM; SAURA-CALIXTO, F; WITTIG DE PENNA, E; MENEZES, EW, eds. Fibra dietética en lberoamérica: Tecnología y salud. Obtención, caracterización, efecto fisiológico y aplicación en alimentos. Proyecto CYTED XI.6 "Obtención y caracterización de fibra dietética para su aplicación en regímenes especiales", CNPq. Varela, São Paulo, 2001. 469p. 
LAJOLO, FM; VANNUCCHI, H. Tabelas de composição de nutrientes em alimentos: Situação no Brasil e necessidades. Arch. Latinoam. Nutr., v.37 (4), p.702-713, 1987.

LEAL, K. Polidextrose: um novo conceito em fibras solúveis prebióticas. In: ILSI BRASIL - International Life Sciences Institute do Brasil. Fibras, prebióticos e probióticos. ILSI BRASIL, São Paulo, 2005. p.59-66.

LI, BW; ANDREWS, KW; PEHRSSON, PR. Individual sugars, soluble, and insoluble dietary fiber contents of 70 high consumption foods. J. Food Comp. Anal., v.15, p.715-723, 2002.

LUDWIG, DS. Glycemic load comes of age. J. Nutr., v.133, p.2695-2696, 2003.

MAINARDI, JA; PURGATTO, E; VIEIRA JÚNIOR, A; BASTOS, WA; CORDENUNSI, BR; NASCIMENTO, JR; LAJOLO, FM. Effects of ethylene and 1-methyl-cyclopropene gene expression and activity profile of alfa-1,4-glucan-phosphorylase during banana ripening. J. Agr. Food Chem., v.54, p.7294-7299, 2006.

MANGELS, AR; HOLDEN, JM; BEECHER, GR; FORMAN, MR; LANZA, E. Carotenoid content of fruits and vegetables: An evaluation of analytic data. J. Am. Diet. Assoc., v.93, p.284-296, 1993.

MANN, J. Dietary carbohydrate: relationship to cardiovascular disease and disorders of carbohydrate metabolism. Eur. J. Clin. Nutr., v.61 (Suppl 1), p.S100-S111, 2007.

MANN, J; CUMMINGS, JH; ENGLYST, HN; KEY, T; LIU, S; RICCARDI, G; SUMMERBELL, C; UAUY, R; van DAM, RM; VENN, B; VORSTER, HH; WISEMAN, M. FAONHO Scientific Update on carbohydrates in human nutrition: conclusions. Eur. J. Clin. Nutr., v.61 (Suppl 1), p.S132-S137, 2007.

MENEZES, EW. Fibra alimentar. In: DANONE RESEARCH CENTRE DANIEL CARASSO, ed. O papel dos probióticos, fibras e água na saúde intestinal. Danone, São Paulo, Brasil, 2007a. p.8-19.

MENEZES, EW. Índice glicêmico como critério de seleção de alimentos. Anais do Simpósio "Novas tendências sobre a importância dos carboidratos na nutrição", Danone SA, São Paulo, 2000b. p.37-45. [Simpósio realizado em São Paulo, dezembro de 1999].

MENEZES, EW. Relatório de Pesquisa Projeto "Estudo da fermentação in vitro e in vivo da fração indigerivel de carboidratos", realizado de 2005-2007 (Processo CNPq n. 301494/2004-5), FCF/USP, 2007c.

MENEZES, EW. Resposta glicêmica de alimentos brasileiros: Estudos em humanos e em animais. Anais do Simpósio "Novas tendências sobre a importância dos carboidratos na nutrição". Danone S A, São Paulo, 2000a. p.63-69. [Simpósio realizado em São Paulo em dezembro de 1999].

MENEZES, EW. Resposta glicêmica de diferentes tipos de pães. Parecer técnico-científico para a Empresa Clariant SA, em 28 de fevereiro de 2007b.

MENEZES, EW. Resposta glicêmica de produtos à base de aveia. Parecer técnico-científico para a Empresa Pepsico do Brasil Ltda., em 24 de outubro de 2006.

MENEZES, EW. Industria y Comércio Alimentário - LATINFOODS. Material de divulgação do LATINFOODS para obtenção da cooperação das indústrias de alimentos no fornecimento de dados analíticos de 
alimentos para implementar a Tabela de Composição de Alimentos da América Latina. BRASILFOODS, São Paulo, versão em espanhol, 2004.

MENEZES, EW; CARUSO, L; LAJOLO, FM. An application of criteria to evaluate quality of dietary fibre data in Brazilian foods. J. Food Compos. Anal., v.13 (4), p.455-473, 2000.

MENEZES, EW; CARUSO, L; LAJOLO, FM. Avaliação da qualidade dos dados de fibra alimentar. Estudo em alimentos brasileiros. In: LAJOLO, FM; SAURA-CALIXTO, F; WITTIG DE PENNA, E; MENEZES, EW, eds. Fibra dietética en Iberoamérica: Tecnología y salud. Obtención, caracterización, efecto fisiológico y aplicación en alimentos. CYTED, CNPq, Varela, São Paulo, 2001. p.165-178.

MENEZES, EW; CARUSO, L; LAJOLO, FM. Uniformização internacional de dados brasileiros de composição de alimentos. Bol. SBCTA, v.31 (2), p.93-104, 1997.

MENEZES, EW; GIUNTINI, EB. Fibra alimentar. In: DUTRA-de-OLIVEIRA, JE; MARCHINI, JS, eds. Ciências nutricionais. $2^{a}$ ed. Sarvier, São Paulo, 2008. (no prelo).

MENEZES, EW; GIUNTINI, EB. Fibra alimentar. In: PHILIPPI, ST, ed. Pirâmide dos alimentos: Fundamentos básicos da nutrição. Manole, São Paulo, 2008. p.341-362.

MENEZES, EW; GIUNTINI, EB. Tabelas e bancos de dados de composição de alimentos. In: DUTRA-de-OLIVEIRA, JE; MARCHINI, JS, eds. Ciências nutricionais. $2^{a}$ ed. Sarvier, São Paulo, 2008 (no prelo).

MENEZES, EW; GIUNTINI, EB; DAN, M; LAJOLO, FM. TBCA-USPI BRASILFOODS: Carbohydrate database. Anais da $7^{\text {th }}$ International Food Data Conference, São Paulo, SP, Brasil, 2007. p.44 (SVII-6), [Conferência realizada em São Paulo, SP, de 21 a 24 de outubro de 2007].

MENEZES, EW; GIUNTINI, EB; LAJOLO, FM. A questão da variabilidade e qualidade de dados de composição de alimentos. Nutrire, v.26, p.63-76, 2003.

MENEZES, EW; GIUNTINI, EB; LAJOLO, FM. Perfil da ingestão de fibra alimentar e amido resistente pela população brasileira nas últimas três décadas. In: LAJOLO, FM; SAURA-CALIXTO, F; WITTIG DE PENNA, E; MENEZES, EW, eds. Fibra dietética en lberoamérica: Tecnología y salud. Obtención, caracterización, efecto fisiológico y aplicación en alimentos. CYTED, CNPq, Varela, São Paulo, 2001. p.433-444.

MENEZES, EW; GIUNTINI, EB; LAJOLO, FM; MORÓN, C. LATINFOODS: Food composition activities in Latin America (2004-2006). J. Food Compos. Anal., v.20, p.704-708, 2007.

MENEZES, EW; GONÇALVES, FAR; GIUNTINI, EB; LAJOLO, FM. Brazilian food composition database: Internet dissemination and other recent developments. J. Food Compos. Anal., v.15 (4), p.453-462, 2002.

MENEZES, EW; LAJOLO, FM, eds. $7^{\text {th }}$ International Food Data Conference -

Food composition and biodiversity. Program and abstracts, BRASILFOODS, Danone, São Paulo, 2007. 120p. [7 $7^{\text {th }}$ International Food Data Conference, realizada em São Paulo de 21 a 24 de outubro de 2007].

MENEZES, EW; LAJOLO, FM, eds. Contenido en fibra dietética y almidón resistente en alimentos y productos iberoamericanos. Proyecto 
CYTED XI.6 "Obtención y caracterización de fibra dietética para su aplicación en regímenes especiales", CNPq, Docuprint, São Paulo, 2000. 121p.

MENEZES, EW; LAJOLO, FM. Aproveitamento do amido do feijão em ensaios de média duração com animais. Ci. Tecnol. Aliment., v.17 (1), p.2-6, 1997.

MENEZES, EW; LAJOLO, FM. Índice glicêmico de alimentos. In: MENEZES, EW; LAJOLO, FM, eds. Avances sobre el uso y las propiedades de los carbohidratos de los alimentos regionales. J K Color Gráfica e Editora Ltda., São Paulo, 2003. p.53-60.

MENEZES, EW; LAJOLO, FM. Inhibition of starch digestion by a black bean alfa-amylase inhibitor, in normal and diabetic rats. Nutr. Rep. Int., v.36 (6), p.1185-1195, 1987.

MENEZES, EW; LAJOLO, FM. Marcadores in vivo e in vitro de carboidratos In: LAJOLO, FM; MENEZES, EW, eds. Carbohidratos en alimentos regionales iberoamericanos. Proyecto CYTED XI.18 "Composición, estructura, propiedades biológicas de carbohidratos y su utilización en alimentos", CNPq, EDUSP, São Paulo, 2006. p.309-334.

MENEZES, EW; LAJOLO, FM. Tabela brasileira de composição de alimentos USP. Anais do III Simpósio Latino Americano de Ciência de Alimentos "Ciência de alimentos: avanços e perspectivas". FEA/UNICAMP, Campinas, 2001, p.233-234 [Simpósio realizado em Campinas, em novembro de 1999]

MENEZES, EW; LAJOLO, FM. Utilização do amido de leguminosas. Arch. Latinoam. Nutr., v.45 (1), p.S270-S272, 1995.

MENEZES, EW; LAJOLO, FM; SERAVALLI, EAG; VANNUCCHI, H; MOREIRA, EA. Starch availability in Brazilian foods: "in vivo" and "in vitro" assays. Nutr. Res., v.16 (8), p.1425-1436, 1996.

MENEZES, EW; LAJOLO, FM; TADINI, C; TRIBESS, T. Depósito de pedido de patente de invenção "Processo de produção de farinha proveniente da banana verde". Instituto Nacional de Propriedade Industrial - I.N.P.I./SP, em 12 de julho de 2007, protocolo $\mathrm{n}^{\circ}$ 018070044163.

MIENEZES, EW; MELO, AT; LIMA, G; LAJOLO, FM. Measurement of carbohydrate components and their impact on energy value of foods. J. Food Compos. Anal., v.17 (3-4), p.331-338, 2004.

MENEZES, EW; MORÓN, C; GIUNTINI, EB. Informe Final da II Conferência Eletrônica FAO/LATINFOODS "Avaliação da qualidade dos dados para bases de dados e tabelas de composição química de alimentos”. LATINFOODS, FAO, USP. São Paulo, 2004. Disponível em: http://www.Ilc.fao.org/foro/latinfoods/pdf/infesp.pdf (epanhol); http://www.rlc.fao.org/foro/latinfoods/pdf/infpor.pdf (português) e http://www.fcf.usp.br/ tabela (português).

MENEZES, EW; RATTO, AT; GIUNTINI, EB; LAJOLO, FM. Composição de alimentos: compilação e uniformização de estruturas para intercâmbio de dados. Braz. J. Food Technol., v.8 (1), p.25-33, 2005.

MONRO, J., BURLINGAME, B. Carbohydrates and related food compounds: INFOODS tagnames, meanings, and uses. J. Food Compos. Anal., v.9, p.100-118, 1996. 
NASCIMENTO, JR; VIEIRA JÚNIOR, A; BASSINELLO, PZ; CORDENUNSI, BR; MAINARDI, JA ; PURGATTO, E; LAJOLO, FM. Effect of ethylene and 1-methyl-cyclopropene on banana amylase expression and starch degradation during fruit ripening. Postharvest Biol. Tec., v.40, p.41-47, 2006.

NATIONAL RESEARCH COUNCIL. Recommended dietary allowances. 10 ed. National Academy Press, Washington, 1989. 284p.

NISHIDA, C; NOCITO, FM; MANN, J. Joint FAOMHO Scientific Update on carbohydrates in human nutrition. Eur. J. Clin. Nutr., v.61 (Suppl 1), p.S1-S137, 2007.

PASCOAL, GB. Fermentabilidade de frutanos da cebola (Allium cepa L.): estudo in vivo, in vitro e do efeito trófico no intestino grosso, São Paulo, 2007. 166p. [Dissertação de Mestrado - Faculdade de Ciências Farmacêuticas da Universidade de São Paulo].

PASCOAL, GB; LAJOLO, FM; MENEZES, EW. Effects of fructans, deriving from onion (Allium cepa L), on indigestible carbohydrates fermentation: in vivo study. Anais do $18^{\text {th }}$ International Congress of Nutrition. Durban, 2005. [Congresso realizado em Durban, África do Sul, de 19 a 23 de setembro de 2005].

RATTO, AT; GIUNTINI, EB; LAJOLO, FM; MENEZES, EW. Formulário para compilação de dados de composição de alimentos: TBCA-USP. Rev. Bras. Cienc. Farm., v.39 (3), p.127-129, 2003.

ROBERFROID, M. Prebiotics: The concept revisited. J. Nutr., v.137, p.S830S837, 2007.

ROSIN, PM; LAJOLO, FM; MENEZES, EW. Measurement and characterization of dietary starches. J. Food Compos. Anal., v.15 (4), p.367-377, 2002.

SALMERON, J; MANSON, JE; STAMPFER, MF; COLDITZ, GA; WING, AL; WILLETT, WC. Dietary fiber, glycemic load, and risk of non-insulindependent diabetes mellitus in women. JAMA, v.277, p.472-477, 1997.

SAURA-CALIXTO, F; GARCIA-ALONSO, A; GOÑI, I; BRAVO, L. In vitro determination of the indigestible fraction in foods: an alternative to dietary fiber analysis. J. Agric. Food Chem., v.48 (8), p.3342-3347, 2000.

SOUZA, AG. Índice glicêmico e carga glicêmica de frutos brasileiros, São Paulo, 2005, 59p. [Dissertação de Mestrado - Faculdade de Ciências Farmacêuticas da Universidade de São Paulo].

SOUZA, MCC. Efeito da suplementação de frutanos e cálcio no metabolismo ósseo de meninas com baixa ingestão de cálcio. São Paulo, 2007, 150p. [Tese de Doutorado - Faculdade de Ciências Farmacêuticas da Universidade de São Paulo].

SOUZA, MCC; LAJOLO, FM; MARTINI, LA; CORREA, NAB; DAN, MCT; MENEZES, EW. Effect of oligofructose-enriched inulin on bone metabolism of girls with low calcium intakes. Braz. Arch. Biol. Technol. (enviado para publicação em dezembro de 2007).

SYDNEY UNIVERSITY GLYCEMIC INDEX RESEARCH SERVICE (SUGIRS). Glycemic index. Disponível em: http://www.glycemicindex.com/sugirs. Acesso em maio de 2007.

THORBURN, A; MUIR, J; PROIETTO, J. Carbohydrate fermentation decreases hepatic glucose output in healthy subjects. Metabolism, v.42 (6), p.780785, 1993. 
TRIBESS, TB; HERNÁNDEZ-URIBE, JP; MÉNDEZ-MONTEALVO, MGC; MENEZES, EW; BELLO-PÉREZ, LA; TADINI, CC. Thermal properties and resistant-starch content of green banana flour (Musa cavendishii) produced at different drying conditions. LWT (enviado para publicação em março de 2008).

TRIBESS, TB; TADINI, CC; MENEZES, EW; LAJOLO, FM. Estudo do efeito do pré-tratamento químico na coloração da farinha de banana verde. Anais do Simpósio Brasileiro sobre o desenvolvimento de novos produtos alimentícios. ITAL, Campinas. 2006. [Simpósio realizado em Campinas, de 08 a 09 de maio de 2006].

UNIVERSIDADE DE SÃO PAULO (USP). Proyecto CYTED XI.6 "Obtención y caracterización de fibra dietética para su aplicación en regímenes especiales". Faculdade de Ciências Farmacêuticas, Departamento de Alimentos e Nutrição Experimental, São Paulo, 2000. Coordenação: MENEZES, EW; LAJOLO, FM. Disponivel em: http://www.fcf.usp.br/cytedxi6.

UNIVERSIDADE DE SÃO PAULO (USP). Tabela Brasileira de Composição de Alimentos-USP, BRASILFOODS, Faculdade de Ciências Farmacêuticas, Departamento de Alimentos e Nutrição Experimental, São Paulo, 1998. Coordenação: MENEZES, EW; LAJOLO, FM. Disponivel em: http://www.fcf.usp.br/tabela. Acesso em fevereiro de 2008.

van DAM, RM; SEIDELL, JC. Carbohydrate intake and obesity. Eur. J. Clin. Nutr., v.61 (Suppl 1), p.S75-S99, 2007.

VANNUCCHI, $\mathrm{H}$; MENEZES, EW; CAMPANA, AO; LAJOLO, FM, eds. Aplicação das recomendações nutricionais adaptadas à população brasileira. Cadernos de Nutrição, SBAN, Ribeirão Preto, v.2, 1990. $155 p$.

VELÁZQUEZ, OC; LEDERER, HM; ROMBEAU, JL. Butyrate and the colonocyte, implications for neoplasia. Digest. Dis. Sci., v.41, p.727-739, 1996.

VENN, BJ; GREEN, TJ. Glycemic index and glycemic load: measurement issues and their effect on diet-disease relationships. Eur. J. Clin. Nutr., v. 61, (Suppl 1), p.S122-S131, 2007.

VIDAL, T; TRIBESS, TB; MENEZES, EW; TADINI, CC. Produção de barra de cereais diet sabor banana com adição de farinha de banana verde (Musa Cavendishii, Var. Nanicão). Anais do Simpósio Latino Americano de Ciência dos Alimentos (SLACA), Campinas, São Paulo, 2007. [Simpósio realizado em Campinas, São Paulo, de 4 a 7 de novembro de 2007].

WORLD HEALTH ORGANIZATION; FOOD AND AGRICULTURE ORGANIZATION (WHO; FAO). Diet, nutrition and prevention of chronic diseases. WHO Technical Report Series, 916. Geneve, 2003.149p. 